\title{
Downscaling of Climate Change in the Hawaii Region Using CMIP5 Results: On the Choice of the Forcing Fields*
}

\author{
Axel Lauer, ${ }^{+}$Chunxi Zhang, And Oliver Elison-Timm \\ International Pacific Research Center, University of Hawai'i at Mānoa, Honolulu, Hawaii \\ YUQING WANG AND KEVIN HAMILTON \\ International Pacific Research Center, and Department of Meteorology, University of Hawai'i at Mānoa, Honolulu, Hawaii
}

(Manuscript received 20 February 2013, in final form 18 June 2013)

\begin{abstract}
The Weather Research and Forecasting (WRF) model has been configured as a regional climate model for the Hawaii region (HRCM) to assess the uncertainties associated with the pseudo-global warming (PGW) downscaling method using different warming increments from phase 5 of the Coupled Model Intercomparison Project (CMIP5) model experiments. Results from 15-km downscaling experiments using warming increments from 10 individual CMIP5 models for the two warming scenarios representative concentration pathway $4.5(\mathrm{RCP} 4.5)$ and $8.5(\mathrm{RCP} 8.5)$ are compared with experiments using multimodel mean warming increments. The results show that changes in $2-\mathrm{m}$ temperatures, $10-\mathrm{m}$ wind speed, rainfall, water vapor path, and trade wind inversion vary significantly among the individual model experiments. This translates into large uncertainties when picking one particular CMIP5 model to provide the warming increments for dynamical downscaling in the Hawaii region. The simulations also show that, despite the large interexperiment spread, a single downscaling experiment using multimodel mean warming increments gives very similar results to the ensemble mean of downscaling experiments using warming increments obtained from 10 individual CMIP5 models. Robust changes of the projected climate by the end of the twenty-first century in the Hawaii region shown by most downscaling experiments include increasing 2-m temperatures with stronger warming at higher elevations, a large increase in precipitable water, and an increase in the number of days with a trade wind inversion (TWI). Furthermore, most experiments agree on a reduction in TWI height and an increase in the TWI strength. Uncertainties in the projected changes in rainfall and 10-m wind speed are large and there is little consensus among the individual downscaling experiments.
\end{abstract}

\section{Introduction}

Coupled atmosphere-ocean global climate models (GCMs) are fundamental research tools to understand and assess climate and its potential future change (Rummukainen 2010). Because of the complexity of these global models and their computational costs, projections of future climate are usually limited to a rather coarse horizontal resolution with a grid spacing of typically $100 \mathrm{~km}$

\footnotetext{
* Supplemental information related to this paper is available at the Journals Online website: http://dx.doi.org/10.1175/JCLID-13-00126.s1.

${ }^{+}$Current affiliation: Institute for Advanced Sustainability Studies, Potsdam, Germany.

Corresponding author address: Axel Lauer, IASS, Berliner Str. 130, 14467 Potsdam, Germany.

E-mail: axel.lauer@iass-potsdam.de
}

or more. Depending on the geographical area of interest, such resolution may not be sufficient for many applications such as those in biogeography and ecology (Diniz Filho et al. 2009; Wiens et al. 2009) or water resource management (Buytaert et al. 2009; Kay et al. 2009). To assess climate risks and vulnerabilities and to develop local and regional strategies for mitigation and adaption of climate change, more detailed projections of future regional climate are needed (Foley 2010). This is particularly the case for regions with very steep and complex topography that impact climate on small horizontal scales. The Hawaiian Islands provide a striking example as they may be represented by only a couple of grid boxes in GCMs while in reality weather and climate in Hawaii are characterized by a diverse and complex system of microclimates with horizontal scales of a few kilometers. Also some aspects of the island climate are very different from those over the surrounding ocean 
region (Giambelluca and Schroeder 1986). High-resolution models are needed to resolve the topography well enough to reproduce the observed climate and to allow for reliable assessments of climate change in this region.

A common approach to simulating local climate is to force a high-resolution regional climate model over a limited domain, taking boundary conditions from global analyses or global model simulations. The forcing fields are provided to the regional model as initial and lateral boundary conditions and typically include temperature, humidity, horizontal wind, sea level pressure, and sea surface temperature. The boundary conditions are of fundamental importance to regional climate modeling and thus a significant source of uncertainties for the projected climate from regional models (e.g., Wu et al. 2005; Wang and Yang 2008).

A first step toward a detailed regional climate change projection for Hawaii was reported by Zhang et al. (2012). They simulated one full year using a nested version of the Weather Research and Forecasting (WRF) model adapted for application to Hawaii. Lateral boundary conditions were specified from reanalyses at the edge of their outer domain, which was about $4000 \mathrm{~km}$ wide and had a horizontal grid spacing of $15 \mathrm{~km}$. The $15-\mathrm{km}-$ resolution outer domain then provided the lateral boundary conditions for an inner domain which was about $500 \mathrm{~km}$ wide and covered the main Hawaiian Islands with a horizontal grid spacing of $3 \mathrm{~km}$. Zhang et al. showed that the results in the inner domain were quite realistic, although deficiencies in the simulated rainfall over the steepest topography regions, particularly on Maui and Oahu, were apparent. More recent simulations with a third nested domain at $1-\mathrm{km}$ resolution around the island of Maui showed a greatly improved rainfall simulation (C. Zhang 2013, personal communication). This triply nested version with $1-\mathrm{km}$ resolution over individual islands seems to be appropriate for downscaling of global climate change projections in the Hawaii region.

Since any fine-resolution warming simulations performed with this model will depend strongly on the global model inputs, it is important to characterize and understand the uncertainty introduced by the range of state-of-the-art global model projections. Unfortunately, the full triply nested model is computationally demanding and so multiple long runs are not possible. Here we consider the range of uncertainty introduced by simulating future climate in just the outer 15-km-resolution domain but for a number of different boundary specifications based on a large sample of different global model projections from different models and different forcing scenarios. We consider the dependence of the results that would be most relevant to the simulation of inner domain meteorology, including the large-scale flow and the vertical atmospheric thermodynamic profiles, particularly characterized by such quantities as trade wind inversion frequency and height.

We will apply the so-called pseudo-global warming (PGW) method (Kimura and Kitoh 2007; Sato et al. 2007; Knutsen et al. 2008; Kawase et al. 2009). In the PGW method, initial and boundary conditions for the regional model integrations are given by the sum of observations (reanalysis data and observed SSTs) and a perturbation or global warming increment estimated from simulations with global coupled models. A basic assumption of the PGW method is a linear coupling of the two components allowing neglecting nonlinear interaction between climate change and the interannual variation of the regional climate in the imposed boundary conditions. A main advantage of the PGW method is that it avoids serious errors in reproducing observed climate with a regional model caused by biases in the boundary conditions from global models (Kimura and Kitoh 2007). Biases in GCMs used to drive a regional climate model are one of the largest difficulties for dynamically downscaling climate (change) (Sato et al. 2007). Extensions to this downscaling concept have been introduced to account for biases in the variance of the simulated presentday climate in the GCMs (Xu and Yang 2012).

Another advantage of the PGW method is that it allows the boundary conditions of the future climate to be based on an ensemble mean of global model results. So one key question motivating this study is to what degree the results obtained by using ensemble mean boundary conditions for the regional model differ from those obtained by averaging downscaling experiments using boundary conditions from individual global models. Given the potentially nonlinear response of winds, clouds, and precipitation to global warming, ensemble mean downscaling results may show different regional features, depending on whether the ensemble mean averaging operation is applied to the GCMs boundary forcing prior to the downscaling or after individually downscaling the multimodel ensemble models with a regional model.

Our approach is similar to the one described by Kawase et al. (2009), who investigated the impact of using selected global warming results from phase 3 of the Coupled Model Intercomparison Project (CMIP3; Meehl et al. 2007) on downscaling results for the baiu rainband in East Asia. In contrast to the region studied by Kawase et al. (2009), the model domain considered here is characterized by extensive surrounding ocean regions. In our study we will use global fields based on climate projections from a large sample (10) of the full set of models from phase 5 of the CMIP (CMIP5; Taylor et al. 2012) that display a range of climate responses. We also repeat our calculations using global model projections based on 

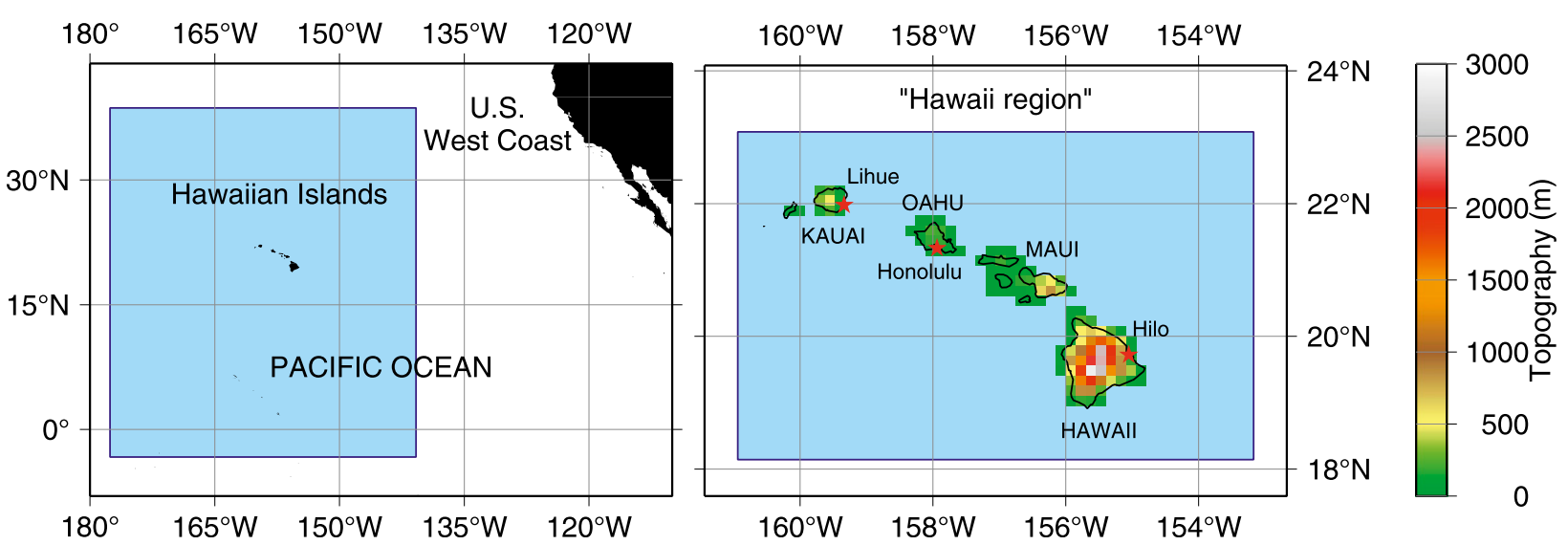

FIG. 1. (left) The 15-km HRCM outer domain and (right) the 3-km inner domain used by Zhang et al. (2012), which we call the Hawaii region $\left(160.9^{\circ}-153.2^{\circ} \mathrm{W}, 18.1^{\circ}-23.1^{\circ} \mathrm{N}\right)$. Also shown (right) is the model topography at a resolution of $15 \mathrm{~km}$.

two different greenhouse gas concentration pathways, the CMIP5 representative concentration pathway 4.5 (RCP4.5) and 8.5 (RCP8.5) scenarios (Taylor et al. 2012). A key issue addressed in this comparison is how the downscaled results for a single model may scale with the mean large-scale warming in the projection.

The regional climate model and the details of our present-day and global warming simulations are described in section 2 . The global warming results for the Hawaii region are discussed in section 3 . Section 4 investigates the multimodel mean properties and the scalability between results for RCP4.5 and RCP8.5. Conclusions are drawn in section 5.

\section{Model and model simulations}

We apply the Hawaii Regional Climate Model (HRCM), which is a version of the WRF model, version 3.3 (Skamarock et al. 2008), specifically configured for the Hawaiian Islands (Zhang et al. 2012). The modifications introduced by Zhang et al. (2012) include a greatly improved set of land surface specifications of surface albedo, land cover/use, green fraction, and soil classification. Here, we use only the outer model domain of the HRCM, which has a horizontal resolution of $15 \mathrm{~km}$ and covers large parts of the central North Pacific $\left(178^{\circ}-141^{\circ} \mathrm{W}, 3^{\circ} \mathrm{S}-\right.$ $\left.39^{\circ} \mathrm{N}\right)$. Zhang et al. (2012) used results from the $15-\mathrm{km}$ domain to drive a $3-\mathrm{km}$ nested domain covering the eight main Hawaiian Islands $\left(160.9^{\circ}-153.2^{\circ} \mathrm{W}, 18.1^{\circ}-23.1^{\circ} \mathrm{N}\right)$. This subdomain (here called the Hawaii region; Fig. 1) is of special interest because uncertainties in the $15-\mathrm{km}$ results are expected to propagate directly into the $3-\mathrm{km}$ results used to assess climate change in the nested domain (or subregion). The HRCM is configured with 31 vertical $\sigma$ levels, of which 14 levels are below $700 \mathrm{hPa}$. The model top is at $10 \mathrm{hPa}$.

We use the Modern-Era Retrospective Analysis for Research and Applications (MERRA) from the National
Aeronautics and Space Administration (NASA) as initial and lateral atmospheric boundary conditions for the present-day model integration (Rienecker et al. 2011). The MERRA data with a horizontal resolution of $0.5^{\circ} \times$ $0.67^{\circ}$ at 6 -h time intervals and at 32 pressure levels between 1000 and $10 \mathrm{hPa}$ are interpolated to the model grid using the standard WRF Preprocessing System (WPS). European Centre for Medium-Range Weather Forecasts (ECMWF) Interim Re-Analysis (ERA-Interim) data are used as initial conditions for soil temperature and soil moisture (Dee et al. 2011). The model temperature, horizontal wind, humidity, surface pressure, and geopotential height are nudged to the lateral boundary conditions within a buffer zone of 15 grid points normal to the lateral boundaries. This buffer zone is excluded in the analyses of the model results shown below.

We prescribe sea surface temperatures (SSTs) using the National Oceanic and Atmospheric Administration (NOAA) optimum interpolation (OI) daily analysis (Reynolds et al. 2007). The SST data are based on daily mean satellite observations from the Advanced Very High Resolution Radiometer (AVHRR) and the Advanced Microwave Scanning Radiometer (AMSR) with a horizontal resolution of $0.25^{\circ} \times 0.25^{\circ}$. The diurnal SST variation is included in our SST forcing and is calculated following the surface energy budget method of Zeng and Beljaars (2005).

The physics modules used in the HRCM configuration are summarized in Table 1. The prescribed greenhouse gas concentrations for carbon dioxide $\left(\mathrm{CO}_{2}\right)$, methane $\left(\mathrm{CH}_{4}\right)$, nitrous oxide $\left(\mathrm{N}_{2} \mathrm{O}\right)$, trichlorofluoromethane (CFC-11), and dichlorodifluoromethane (CFC-12) are summarized in Table 2 for all model experiments. More details on the model and an evaluation of the model performance with observations in the Hawaii region can be found in Zhang et al. (2012).

In this study, we performed a present-day experiment and a set of global warming experiments. For the 
TABLE 1. Physics schemes used in the HRCM configuration of the WRF model.

\begin{tabular}{|c|c|c|}
\hline Physics & Scheme & Remarks \\
\hline Cloud microphysics & $\begin{array}{l}\text { WRF single-moment 6-class } \\
\text { microphysics scheme (WSM6) }\end{array}$ & $\begin{array}{l}\text { Cloud droplet number concentration changed } \\
\text { from } 300 \text { to } 55 \mathrm{~cm}^{-3} \text {; autoconversion from } \\
\text { Khairoutdinov and Kogan (2000) }\end{array}$ \\
\hline $\begin{array}{l}\text { Radiation (shortwave } \\
\text { and longwave) }\end{array}$ & $\begin{array}{l}\text { Community Atmosphere Model, } \\
\text { version } 3 \text { (CAM3) }\end{array}$ & Called every 15 min (every 12 th time step) \\
\hline Boundary layer physics & Mellor-Yamada-Janjić & Called every time step $(75 \mathrm{~s})$ \\
\hline Land surface processes & Noah land surface model (LSM) & $\begin{array}{l}\text { Improved land surface specifications for the } \\
\text { Hawaiian Islands (Zhang et al. 2012) }\end{array}$ \\
\hline Cumulus convection & Tiedtke scheme & Called every time step $(75 \mathrm{~s})$ \\
\hline
\end{tabular}

present-day experiment, the model was initialized on 1 December 1999 and integrated continuously until 31 December 2002 using observed SSTs and lateral boundary conditions. The El Niño-Southern Oscillation (ENSO) cycle has a strong impact on the interannual variability of rainfall in Hawaii with El Niño winters being statistically dryer and La Niña winters being statistically wetter than average (Chu and Chen 2005). Based on observed Niño-3.4 SST anomalies, the first half of the year 2000 is characterized by La Niña conditions, and the second half of the year 2002 is characterized by El Niño conditions. The year 2001 is in an ENSO neutral state. We therefore do not expect the 3-yr integration period 2000-02 in this study to be significantly biased toward any particular ENSO state. Although a 3-yr mean cannot represent the present-day climate well because El Niño, La Niña, and ENSO neutral years are generally not distributed equally, our main objective is to evaluate the sensitivity of the PGW downscaled results to the choice of forcing fields.

For the global warming experiments, we apply the PGW method using results from coupled GCMs to drive the regional climate model. In this method, the initial and lateral boundary conditions are taken from the 6-h reanalysis data and observed SSTs used for the presentday experiment with global warming increments added on top of the SST and the atmospheric variables. The global warming increments are defined as the monthly averaged differences between the present-day climate and the projected climate by the end of the twenty-first century from global coupled models providing data to the CMIP5. The monthly mean global warming increments are interpolated linearly in time before being added to the 6-hourly reanalysis data used to create the lateral boundary conditions for HRCM. We used data from 10 CMIP5 models (Table 3 ) to calculate the 100-yr global warming increments by subtracting means for each calendar month of the year averaged over the years 1990-99 from corresponding results averaged over the years 2090-99. The models were randomly picked with the constraint that only one model is selected from each climate institute or model family, and, as we show below, the selected GCMs display a large range of climate responses to the same enhanced greenhouse forcing. The present-day results were taken from the CMIP5 twentieth-century simulations conducted with the best record of natural and anthropogenic climate forcing ("historical" experiments). The conditions for the end of the twenty-first century were obtained from projections for the two emission scenarios RCP4.5 and RCP8.5. RCP4.5 is a medium-low RCP with stabilization from the year 2150 onward leading to an approximate global anthropogenic radiative forcing of $4.5 \mathrm{~W} \mathrm{~m}^{-2}$. RCP8.5 is a high RCP with emissions stabilizing after 2100 and concentrations stabilizing after 2200. The approximate global anthropogenic radiative forcing for RCP8.5 is $8.5 \mathrm{~W} \mathrm{~m}^{-2}$. If there are multiple ensemble members available for any given model and model experiment, we only consider the first ensemble member in our analysis, r1i1p1, as the differences in the $10-\mathrm{yr}$ mean warming signals among the individual models are much larger than those between individual ensemble members from the same model. In addition to the global warming increments from the individual CMIP5 models, we also calculated the multimodel mean warming increments by averaging over all 10 global models. The multimodel means were calculated for both RCP4.5 and RCP8.5 separately.

The PGW method is useful in providing boundary conditions for downscaling experiments particularly in regions that are challenging for global models to

TABLE 2. Greenhouse gas concentrations in the HRCM experiments for present-day conditions and conditions at the end of the twenty-first century (RCP4.5 and RCP8.5).

\begin{tabular}{lccc}
\hline \hline & $\begin{array}{c}\text { Present day } \\
(2000-02)\end{array}$ & RCP4.5 (2100) & RCP8.5 (2100) \\
\hline $\mathrm{CO}_{2}(\mathrm{ppm})$ & $369-373$ & 538 & 936 \\
$\mathrm{CH}_{4}(\mathrm{ppm})$ & $1760-1782$ & 1576 & 3751 \\
$\mathrm{~N}_{2} \mathrm{O}$ (ppb) & $316-318$ & 372 & 435 \\
$\mathrm{CFC}-11(\mathrm{ppt})$ & $267-263$ & 32 & 26 \\
$\mathrm{CFC}-12(\mathrm{ppt})$ & $535-533$ & 185 & 167 \\
\hline
\end{tabular}




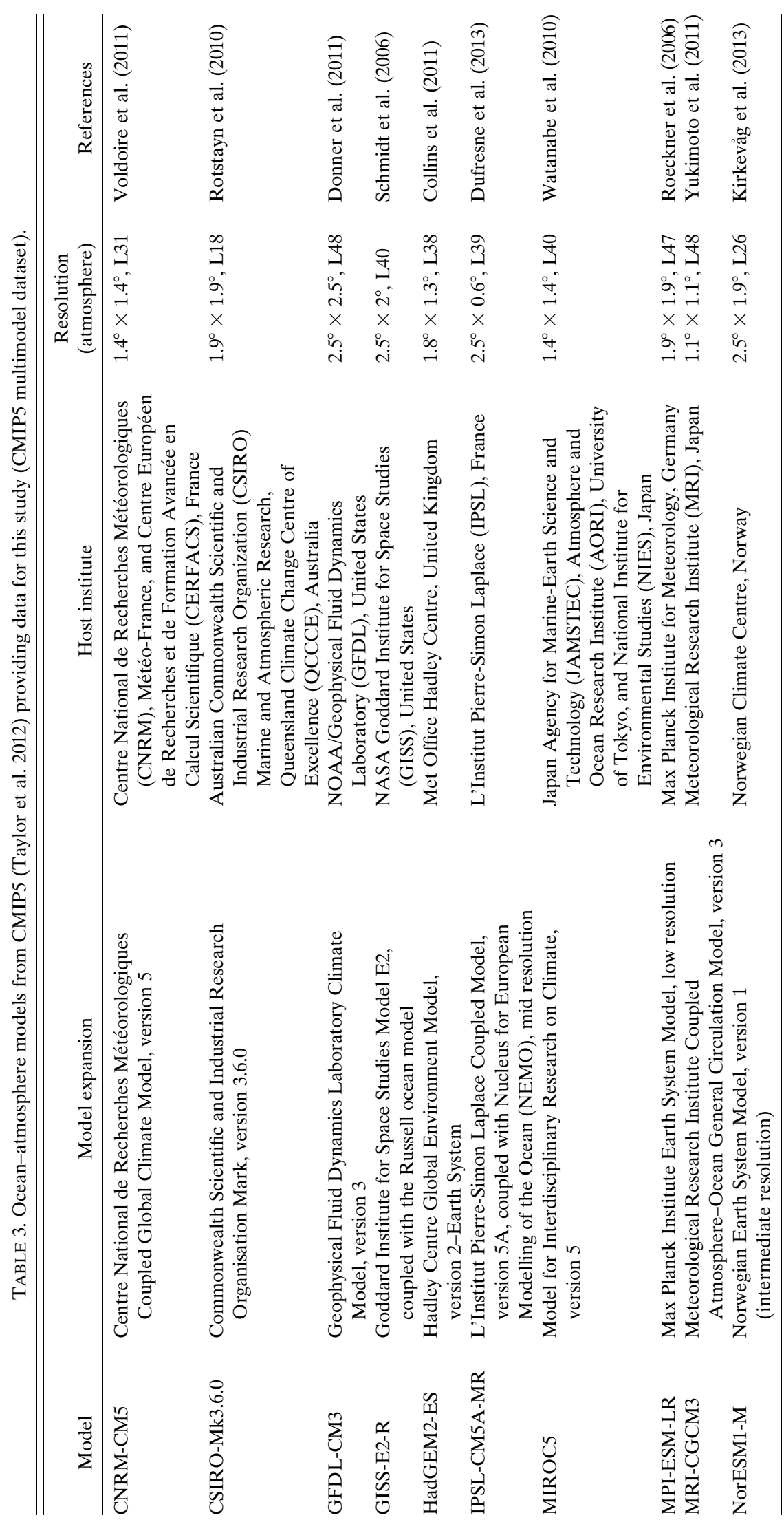



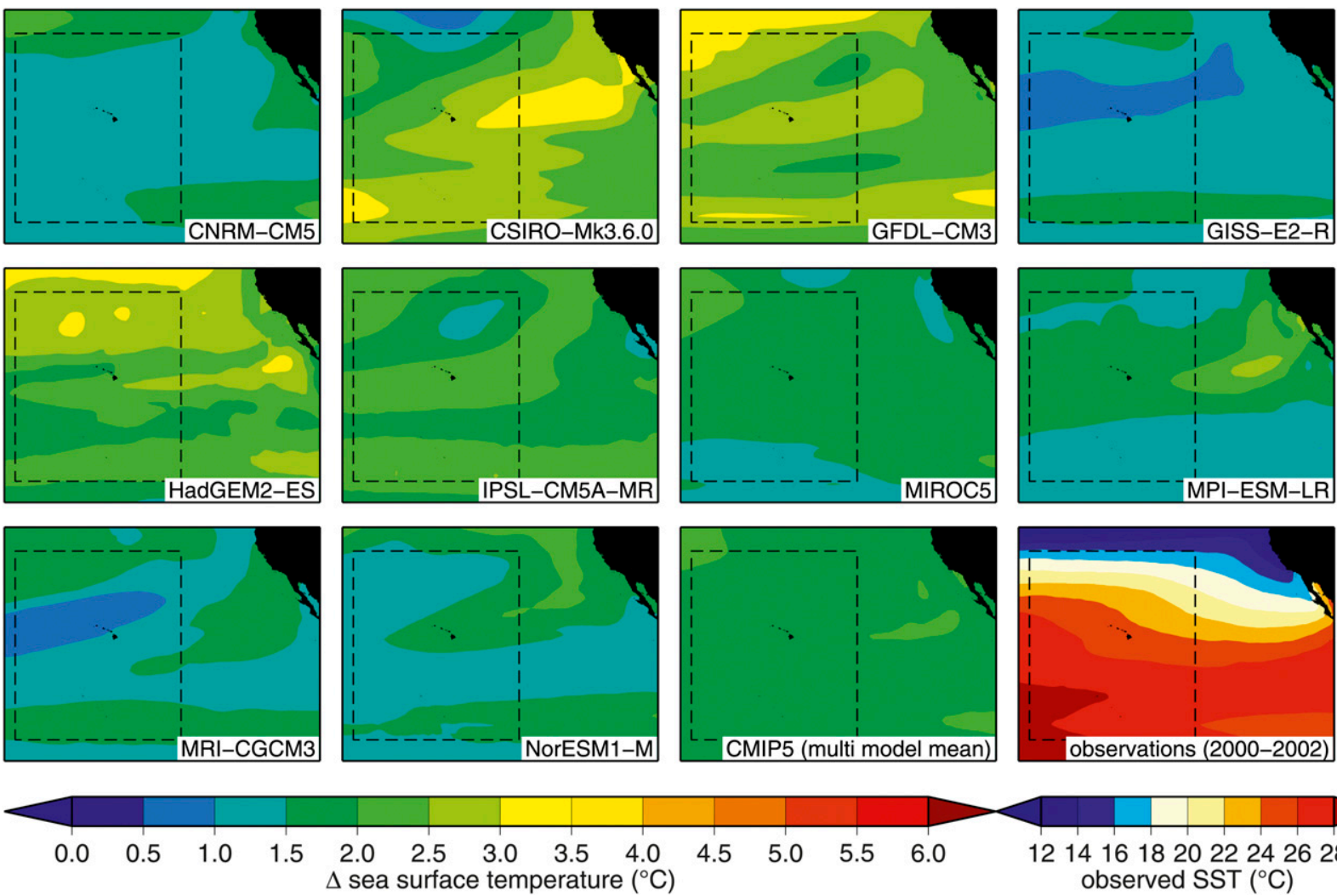

121416182022242628 observed SST $\left({ }^{\circ} \mathrm{C}\right)$

FIG. 2. Differences in annual average SST between the end of the twenty-first-century (2090-99) and late-twentieth-century conditions (1990-99) in the Pacific Ocean. Shown are the results of individual CMIP5 models for the RCP4.5 scenario as well as (bottom, right center) the CMIP5 multimodel mean averaged over all 10 individual models. In addition, the (bottom right) observed SSTs for 2000-2002 are shown. Land surfaces are drawn in black. The dashed boxes show the HRCM domain with the Hawaiian Islands in the center.

simulate. However, the PGW method has some significant limitations. Most notably, the PGW method cannot adequately capture any potential changes in the variability from daily to interannual time scales of the climate system. The PGW method assumes the same variability in the boundary conditions in the present day and in the future climate. For the Hawaii region, for example, we expect changes in the ENSO cycle to be relevant. At this stage, however, it is not clear whether and if so how the variability in the frequency or strength of ENSO events will change in the future climate (Collins et al. 2010; Vecchi and Wittenberg 2010). Furthermore, the use of prescribed SSTs does not allow for possible atmosphere-ocean feedbacks in our regional model, which could become relevant for multiyear integrations. These limitations have to be kept in mind when analyzing and interpreting the downscaling results obtained with the PGW method. Yoshikane et al. (2012) investigate the performance of the PGW method for future climate change in East Asia by comparing results from downscaling global model output directly with those obtained from downscaling with the PGW method. They find that differences in downscaled temperature and precipitation changes from both methods are usually small for their model domain but the differences depend on the geographical area chosen for the downscaling.

One component of the warming increments is illustrated in Figs. 2 and 3, which show the differences in annual average SST between the conditions for the end of the twenty-first century (2090-99) and the late twentieth century (1990-99) from the CMIP5 models for the RCP4.5 and RCP8.5 scenarios, respectively. The CMIP5 models display a large spread in SST warming amplitude and pattern. For RCP4.5, the average SST warming increments in the HRCM domain are between 1.4 (CNRMCM5 and MRI-CGCM3) and $2.4^{\circ} \mathrm{C}$ (CSIRO-Mk3.6.0 and GFDL-CM3) and the CMIP5 multimodel mean SST warming is $1.8^{\circ} \mathrm{C}$ (see Table 3 for expanded model names). For RCP8.5, the average SST warming increment is between $2.4^{\circ}$ (GISS-E2-R) and $4.5^{\circ} \mathrm{C}$ (GFDL-CM3) and the $\mathrm{RCP} 8.5$ multimodel mean SST increment is $3.4^{\circ} \mathrm{C}$. Most of the CMIP5 models show an enhanced SST warming in the equatorial Pacific. In general, the geographical patterns of ocean surface warming vary widely throughout the HRCM model domain among the individual CMIP5 models. For example, while HadGEM2-ES 

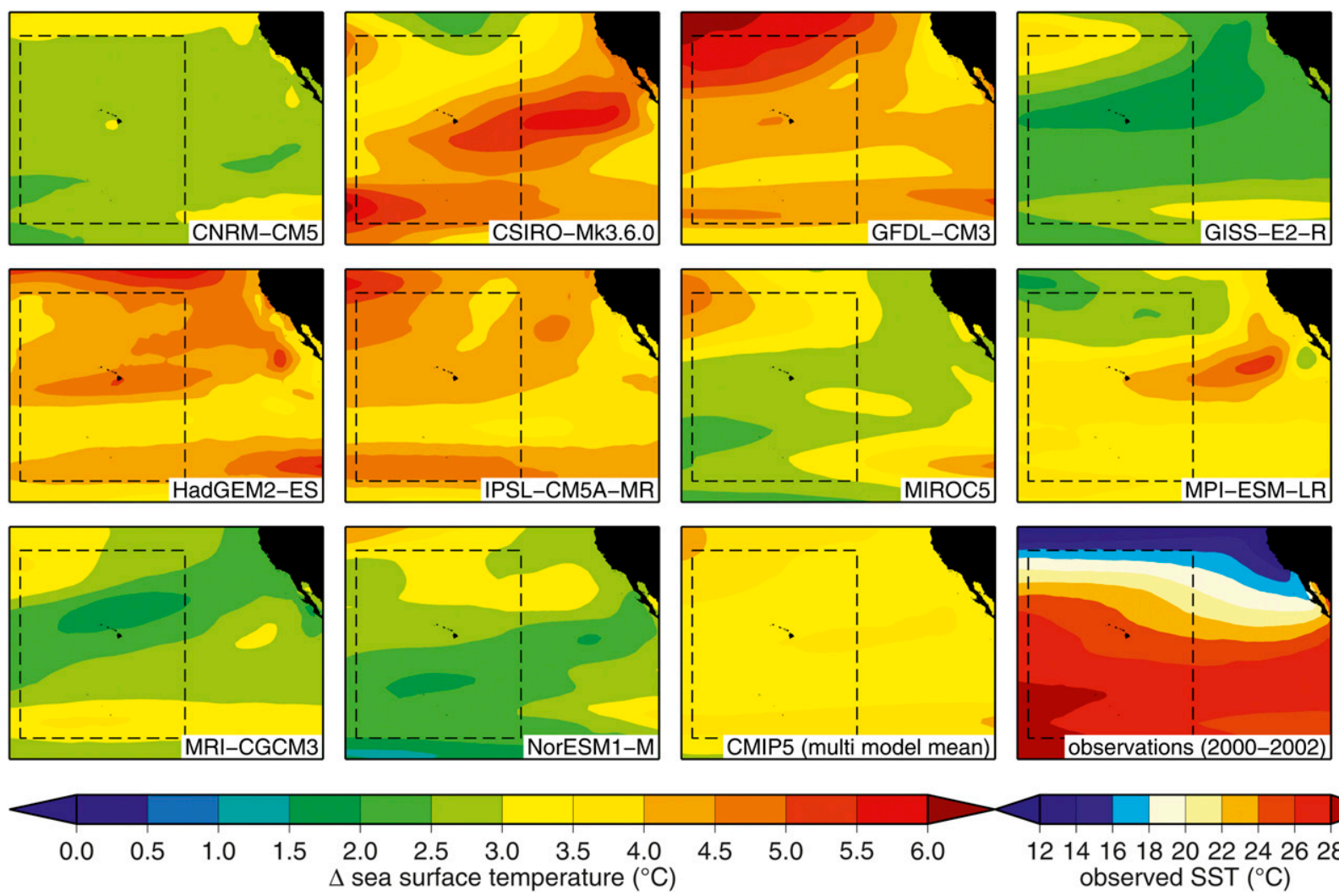

121416182022242628

observed SST $\left({ }^{\circ} \mathrm{C}\right)$

FIG. 3. As in Fig. 2, but for the RCP8.5 scenario.

shows a local maximum in SST warming near the Hawaiian Islands, MRI-CGCM3 shows a local minimum in SST warming in the same region.

The first month of each model integration (viz., December 1999 and 2099) is considered as the model spinup period for the model physics and is excluded from our analysis below.

\section{Global warming results}

\section{a. 2-m temperatures}

The near surface temperatures over the Hawaiian Islands are strongly influenced by the surrounding ocean and the local topographic elevation. Figure 4 shows the probability density functions (PDFs) of daily mean 2-m temperatures $T_{2 \mathrm{~m}}$ averaged over all HRCM land grid cells in the Hawaii region with an elevation of less than $200 \mathrm{~m}$ (see also Fig. 1). The results are given for the present-day simulation as well as for both the RCP4.5 and RCP8.5 global warming simulations. Similar to the spread in SST warming increments among the CMIP5 models, the downscaling results show increases in $T_{2 \mathrm{~m}}$ between $1.2^{\circ}$ (GISS-E2-R and MRI-CGCM3) and $2.9^{\circ} \mathrm{C}$ (CSIRO-Mk3.6.0 and GFDL-CM3) for RCP4.5 and between $2.3^{\circ}$ (GISS-E2-R) and $4.9^{\circ} \mathrm{C}$ (GFDL-CM3 and HadGEM2-ES) for RCP8.5. The projected annual average changes in 2-m temperatures from the simulations using the ensemble mean warming increments (RCP4.5: $2.0^{\circ} \mathrm{C} ; \mathrm{RCP} 8.5: 3.8^{\circ} \mathrm{C}$ ) are very close to the mean of all model experiments using warming increments from individual CMIP5 models. This is somewhat expected as the daily mean 2-m temperatures of low-lying grid cells are tightly connected to the SST. In addition to the spread in the average warming, we also find considerable differences in the shape of the $T_{2 \mathrm{~m}}$ PDFs among the individual model experiments. While the width of the $T_{2 \mathrm{~m}}$ PDF does not change significantly in the warming experiments using many of the model warming increments (e.g., from CNRM-CM5), interestingly the PDFs are significantly wider in the experiments from some of the models: notably, CSIRO-Mk3.6.0 and HadGEM2-ES.

For comparison, Fig. 4 also shows the PDF of the present-day daily maximum 2-m temperature. For the RCP8.5 scenario, 4 out of the $10 \mathrm{HRCM}$ runs using warming increments from individual models (CSIRO-Mk3.6.0, GFDL-CM3, HadGEM2-ES, and IPSL-CM5A-MR) predict daily mean temperatures exceeding the highest present-day maximum temperatures. 

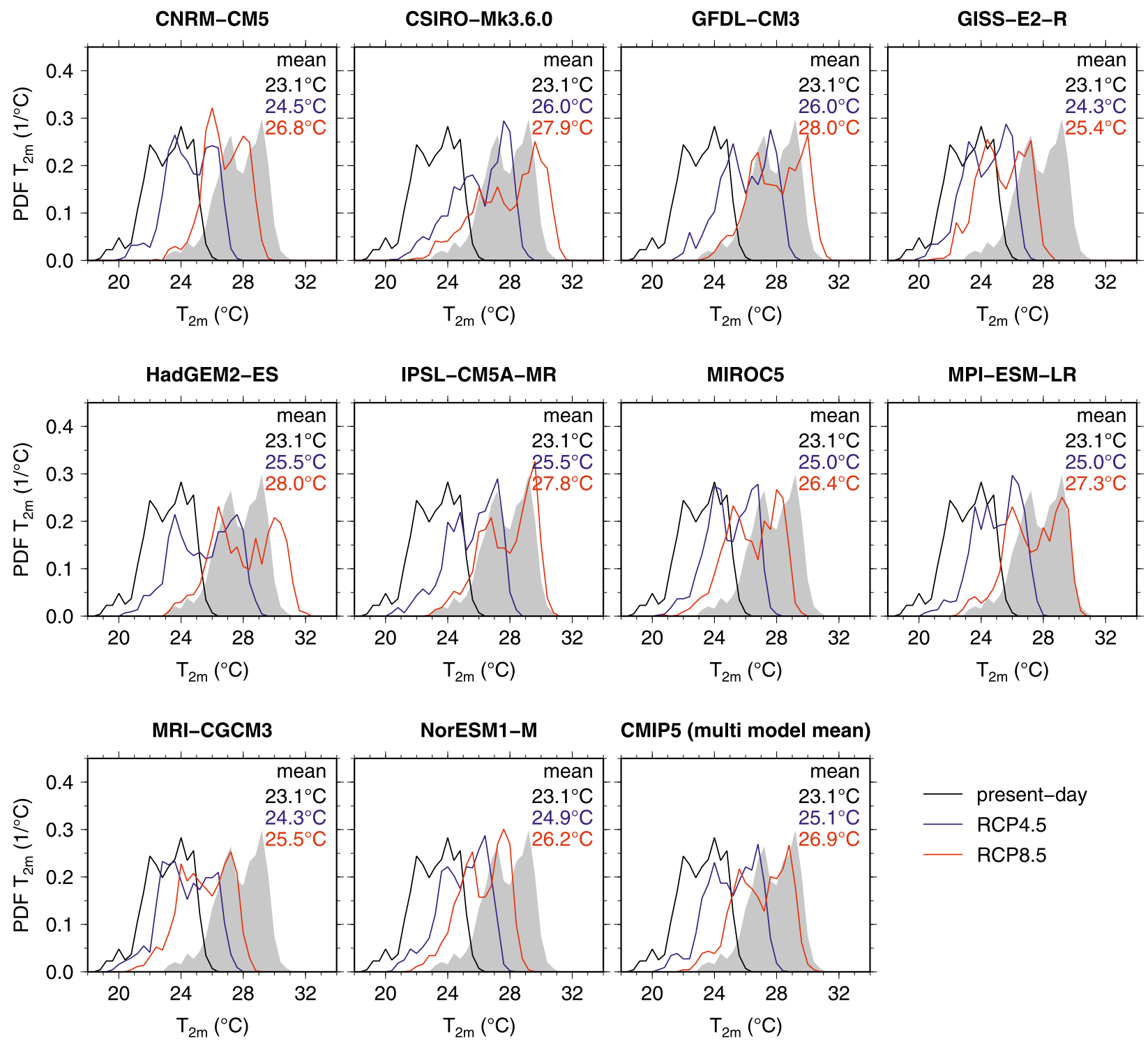

CMIP5 (multi model mean)

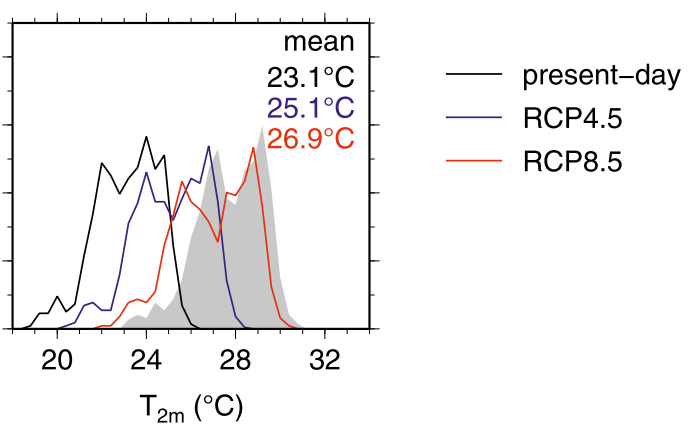

FIG. 4. PDFs of the daily mean $2-\mathrm{m}$ temperature $T_{2 \mathrm{~m}}$ averaged over all land grid cells in the Hawaii region $\left(160.9^{\circ}-153.2^{\circ} \mathrm{W}, 18.1^{\circ}-\right.$ $\left.23.1^{\circ} \mathrm{N}\right)$ with an elevation of less than $200 \mathrm{~m}$. Shown are HCRM results from 3 years $(2000-02)$ using the warming increments from 10 individual CMIP5 models and the (bottom right) CMIP5 multimodel mean. The black curves show the present-day results, and the blue and red lines curves are for the RCP4.5 and RCP8.5 scenarios, respectively. The area shaded in gray shows the PDF of present-day daily maximum $T_{2 \mathrm{~m}}$. The numbers in the top right of the panels give the 3-yr annual mean $T_{2 \mathrm{~m}}$.

\section{b. Precipitable water}

The column precipitable water or water vapor path (WVP) is an important quantity with direct implications for moisture, clouds, and possible rainfall amounts. Changes in WVP for the $15-\mathrm{km}$ domain are therefore highly relevant to further downscaling of climate change over the Hawaiian Islands using higher-resolution nested domains. Figure 5 shows the PDFs of the 6-hourly WVP between January 2000 and December 2002 averaged over the entire Hawaii region for each of the 23 HRCM simulations. All global warming simulations show an increase in WVP between 6\% (GISS-E2-R) and $22 \%$ (GFDL-CM3 and IPSL-CM5A-MR) for RCP4.5 and between $12 \%$ (GISS-E2-R) and $40 \%$ (GFDL-CM3) for RCP8.5. The WVP changes from the model experiment using multimodel mean warming increments (RCP4.5: 15\%; RCP8.5: 30\%) are again very close to the average change in WVP over all model experiments using warming increments from individual CMIP5 models. As for the PDFs of the projected future 2-m temperatures, the PDFs of WVP differ significantly in shape among the individual model experiments. The majority of the individual model runs, as well as the model 

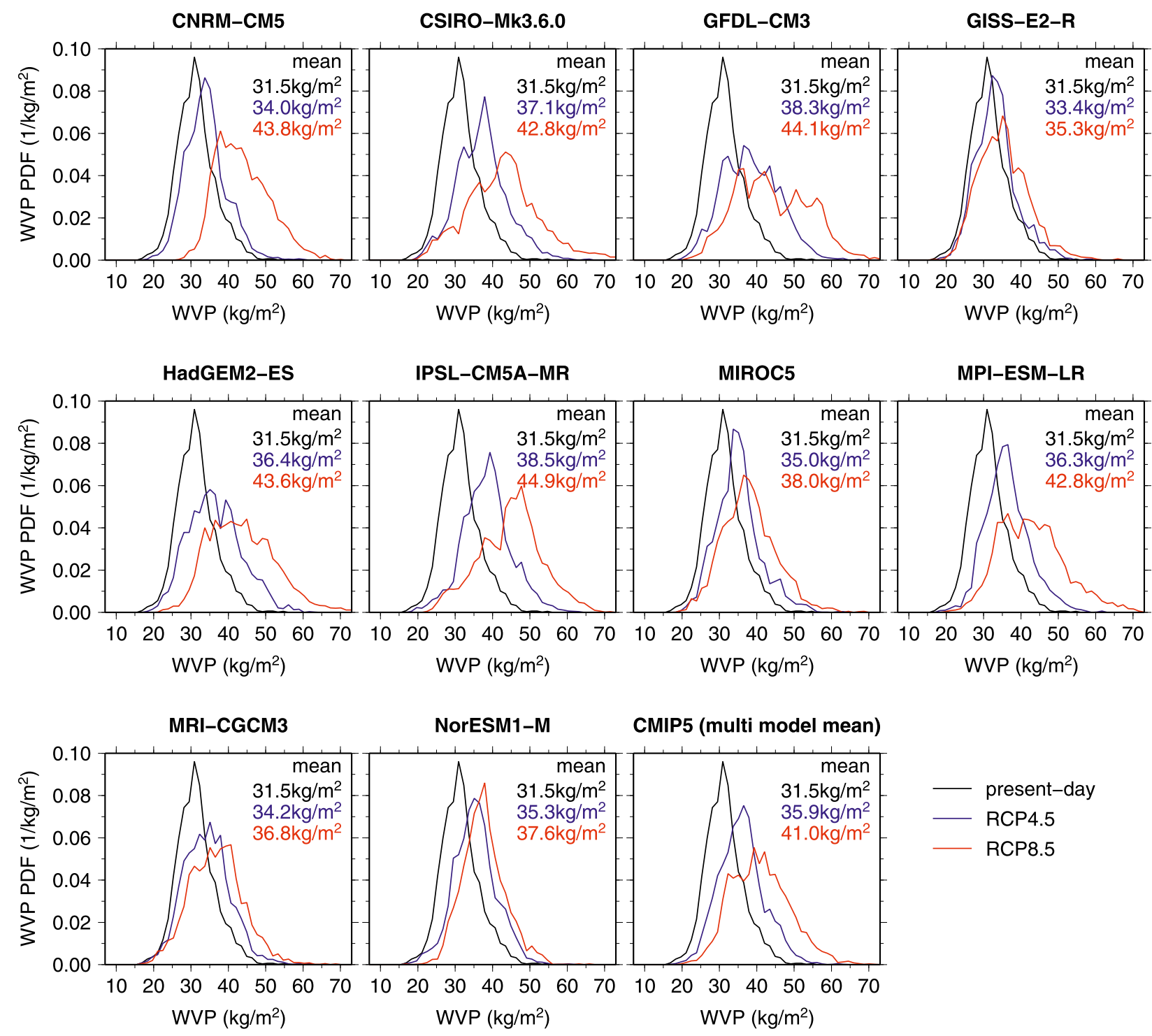

CMIP5 (multi model mean)

FIG. 5. As in Fig. 4, but for the 6-hourly WVP values averaged over all grid cells in the Hawaii region $\left(160.9^{\circ}-153.2^{\circ} \mathrm{W}, 18.1^{\circ}-23.1^{\circ} \mathrm{N}\right)$.

experiment using the multimodel mean warming increments, shows a widening of the WVP PDF with warming (RCP4.5) and even greater widening with stronger warming (RCP8.5). It is noteworthy that the widening of the WVP PDF as well as the large increase in the amount of precipitable water is robust among all 22 of the warming cases investigated here.

\section{c. Rainfall}

Figures 6 and 7 show 3-yr mean changes in daily precipitation rates from all global warming experiments compared with the HRCM present-day reference run. The downscaling results using warming increments from individual models show a large interexperiment spread for both RCP4.5 and RCP8.5.
Most downscaling experiments show a southward shift of the rainfall associated with the intertropical convergence zone (ITCZ). Notable exceptions of this southward shift are the experiments using warming increments from MPI-ESM-LR (RCP4.5 and RCP8.5) and from MIROC5 (RCP4.5). In those two cases, the HRCM simulates a northward shift of the ITCZ rainband. Throughout most of the domain north of the ITCZ region, the individual warming experiments display considerable disagreement in both the amplitude and geographical pattern of the projected precipitation changes. The simulated absolute changes in daily rainfall in the Hawaii region are small. Most experiments show small reductions over the ocean facing the windward (northeast) side of the Big Island. 

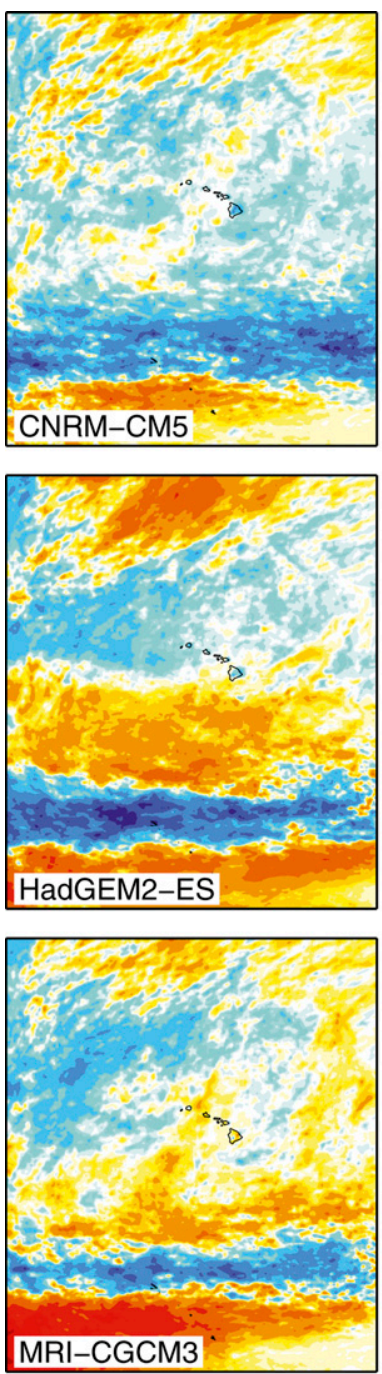
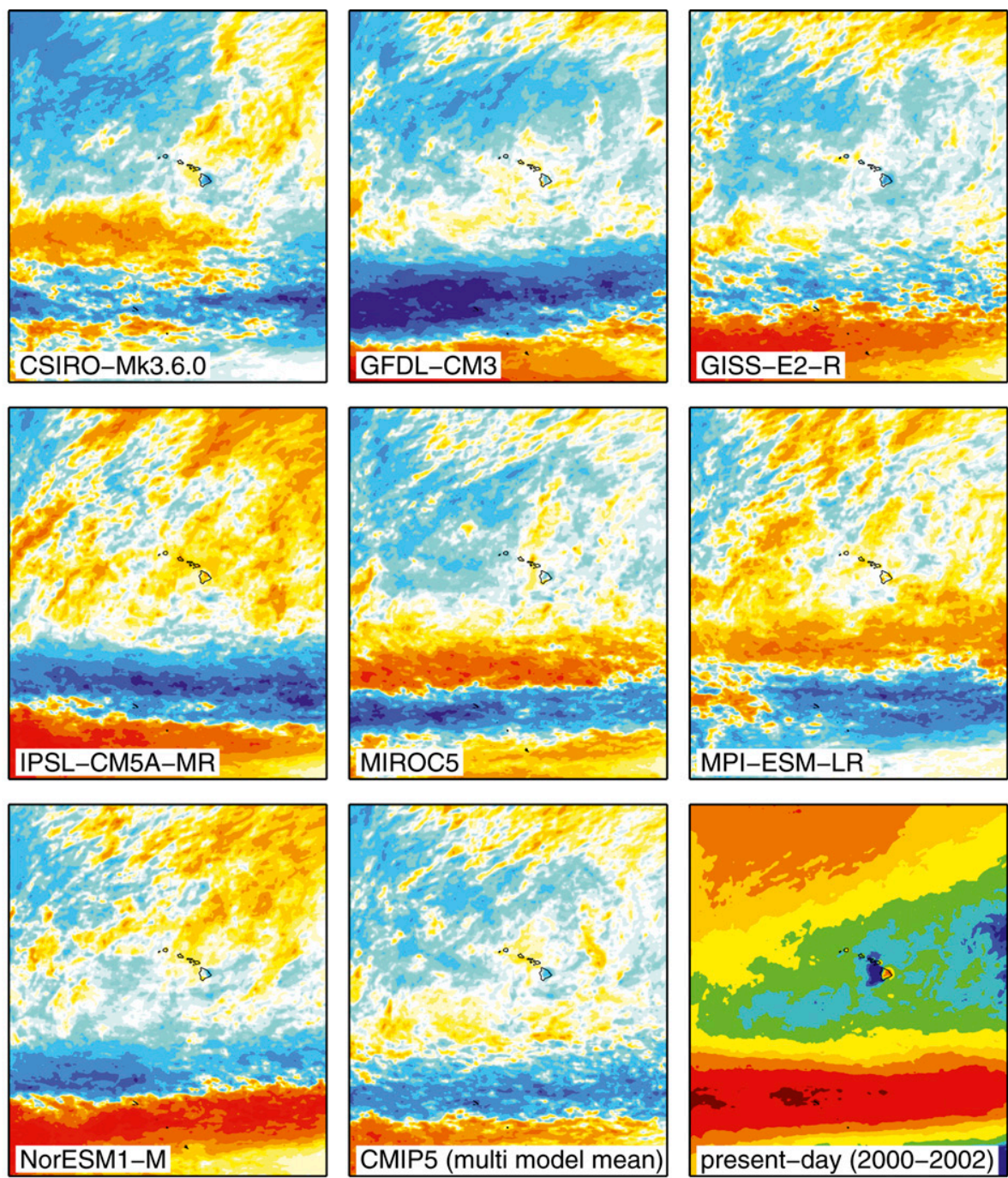
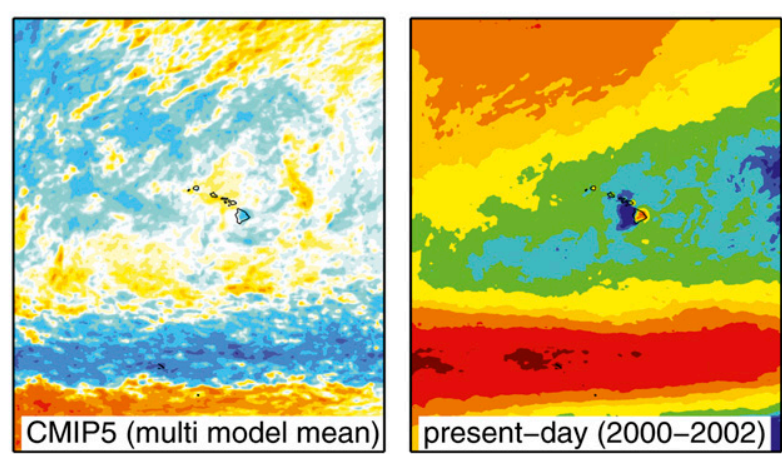

$-10.0-5.0-3.0-2.0-1.0-0.5-0.3-0.2-0.10 .00 .10 .20 .3 \quad 0.51 .02 .03 .05 .010 .0$

$\Delta$ rain (mm/day)

0.20 .30 .51 .02 .03 .05 .010 .0

present-day (mm/day)

FIG. 6. Changes in 3-yr annual mean precipitation from HRCM for the RCP4.5 scenario. Shown are the results using the warming increments from 10 individual CMIP5 models and (bottom, right center) the CMIP5 multimodel mean. In addition, the (bottom right) 3-yr mean precipitation from HRCM for 2000-2002 is shown.

Furthermore, most of our warming experiments show an increase in summer precipitation (May-October) and a decrease in winter precipitation (NovemberApril) in the Hawaii region (see Figs. S1-S4 of the supplementary material). Given the large interexperiment pread in the projected precipitation changes, results from the two downscaling experiments using multimodel mean warming increments have a remarkably similar geographical pattern with the amplitude of the rainfall changes in the ITCZ region being larger in the RCP8.5 experiment than in the RCP4.5 experiment.

\section{d. Trade wind inversion and atmospheric stability}

Weather and climate in the Hawaii region are dominated by trade winds, which are present in about $80 \%$ of all days (Cao et al. 2007). During trade wind conditions the marine boundary layer is usually capped by a trade wind inversion (TWI), which has a strong impact on clouds and rainfall over the Hawaiian Islands (Giambelluca and Nullet 1991). Any changes in the number of days with a TWI present or changes in the height and strength of the TWI could have significant impacts on rainfall and moist deposition over the islands. To identify the TWI in the 

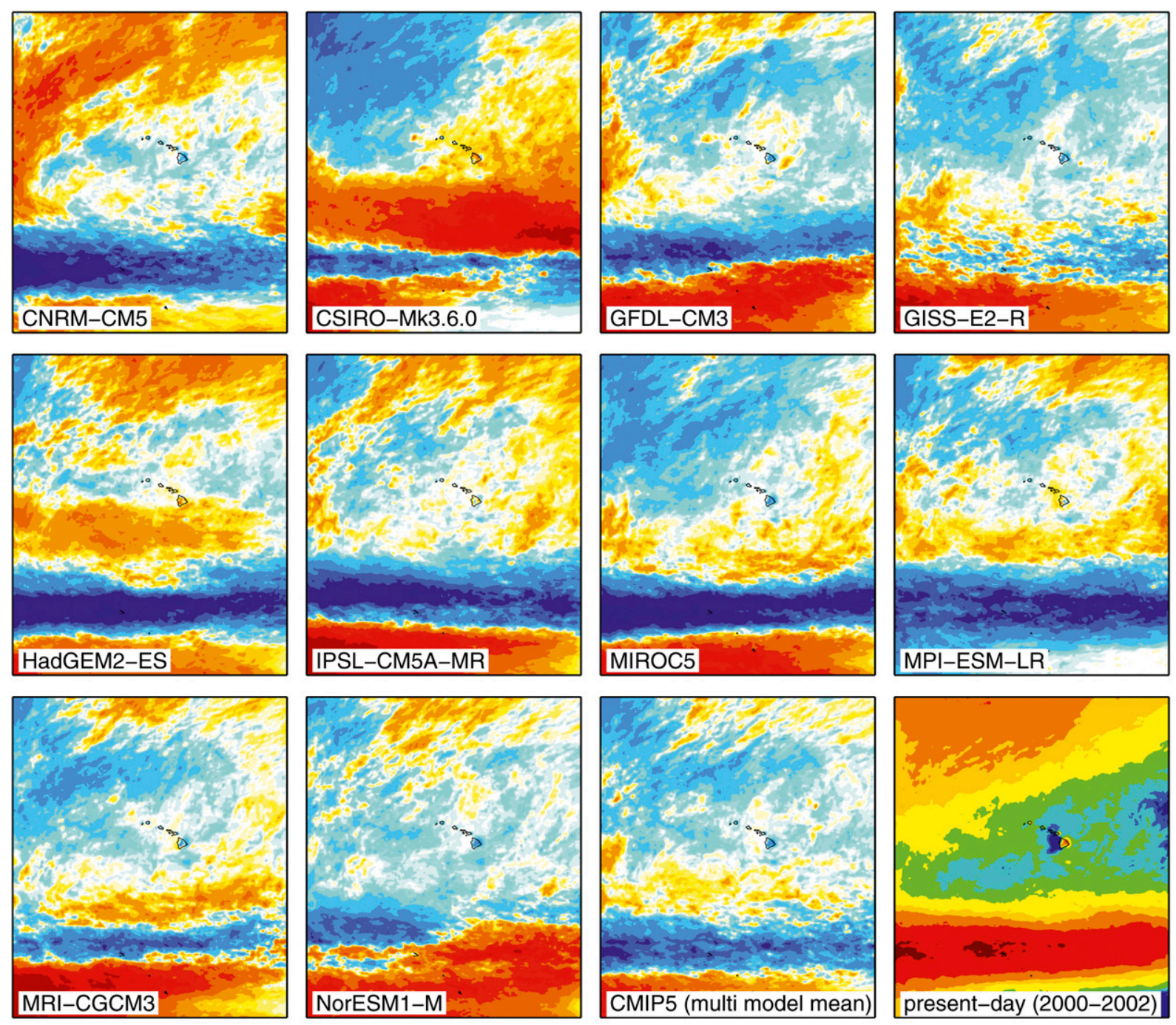

-10.0-5.0-3.0-2.0-1.0-0.5-0.3-0.2-0.10.0 0.10 .20 .30 .51 .02 .03 .05 .010 .0

$\Delta$ rain ( $\mathrm{mm} /$ day)

0.20 .30 .51 .02 .03 .05 .010 .0 present-day (mm/day)

FIG. 7. As Fig. 6, but for the RCP8.5 scenario.

model output we follow the criteria proposed by $\mathrm{CaO}$ et al. (2007):

1) The inversion height is assumed to lie in the 950-600$\mathrm{hPa}$ range. This excludes potential surface radiative inversions and inversions above $600 \mathrm{hPa}$ caused by the melting of cloud ice particles.

2) The TWI layer is identified as a layer with increasing temperature with height together with a decreasing relative humidity with height.

3) Each vertical profile has at most one TWI layer. In profiles displaying multiple temperature inversion layers, the layer with the greatest decrease in relative humidity with height is defined to be the TWI layer.
Figure 8 shows the PDFs of the modeled TWI height calculated from 6-hourly data of the 3 years for each model experiment. The simulated 3-yr annual mean TWI height in the present-day experiment $(2630 \mathrm{~m})$ is about $30 \%$ higher than domain averages over the Hawaii region calculated from Constellation Observing System for Meteorology, Ionosphere, and Climate (COSMIC) observations (2020 m) and about $25 \%$ higher than estimates from Cloud-Aerosol Lidar and Infrared Pathfinder Satellite Observations (CALIPSO; 2110m) (Zhang et al. 2012). The number of days with a TWI present is underestimated by the HRCM by about $13 \%$ giving a TWI in $70 \%$ of the days, whereas observations 

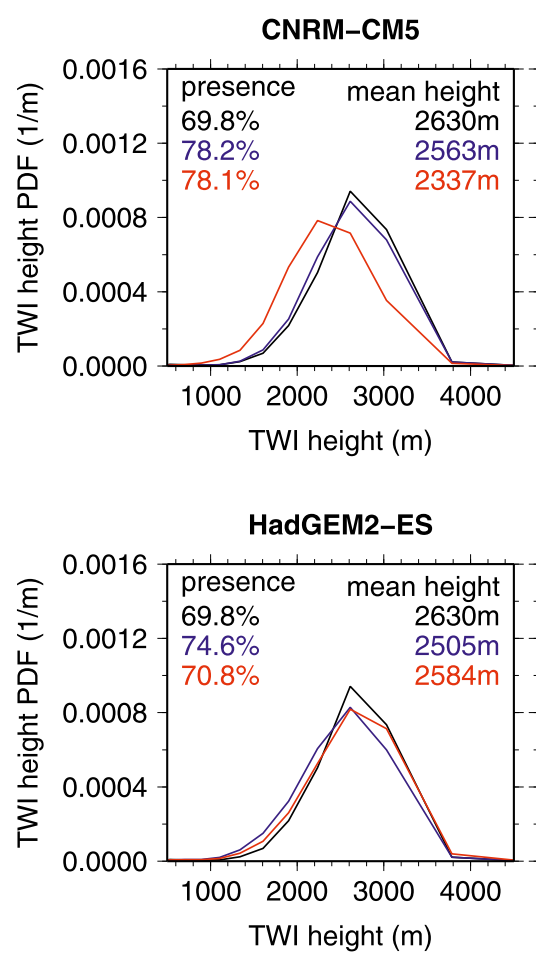

MRI-CGCM3

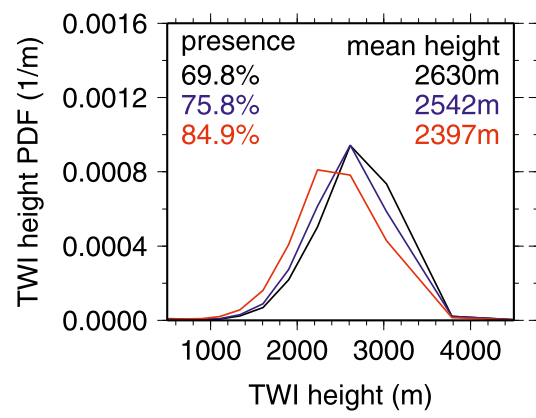

CSIRO-Mk3.6.0

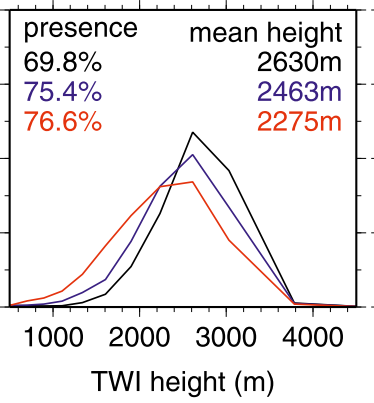

IPSL-CM5A-MR

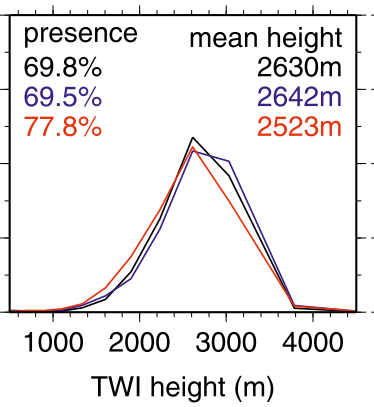

NorESM1-M

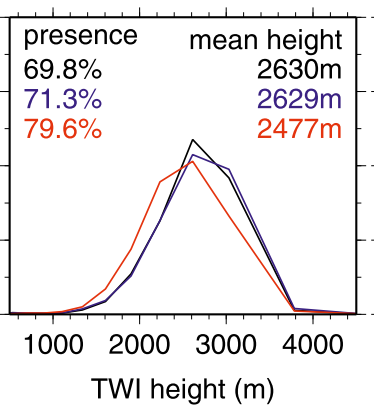

GFDL-CM3

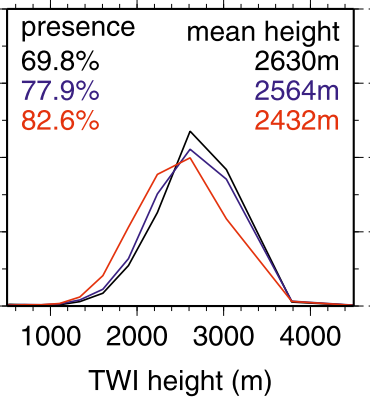

MIROC5

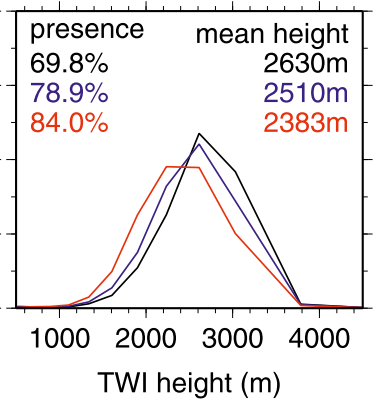

CMIP5 (multi model mean)

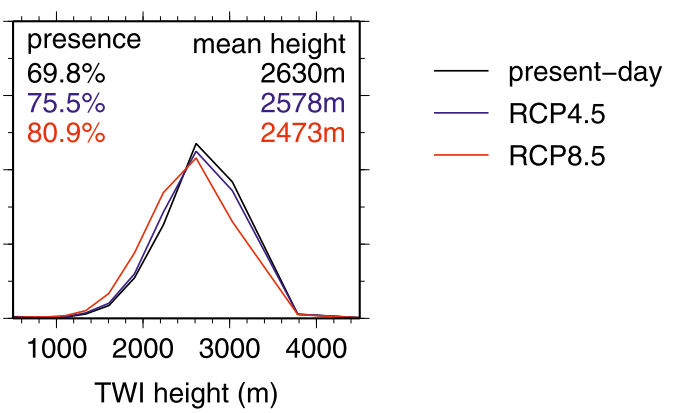

GISS-E2-R

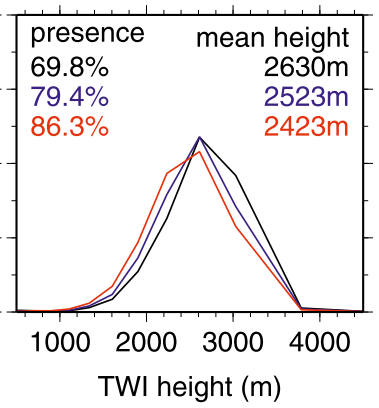

MPI-ESM-LR

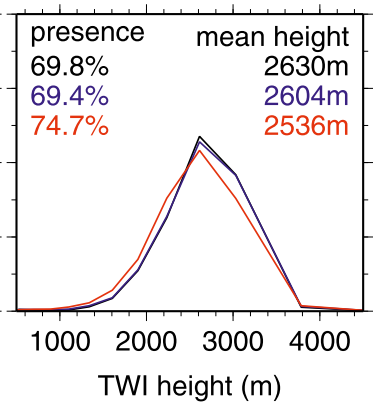

FIG. 8. As in Fig. 4, but for the TWI height 6-hourly values averaged over all grid cells in the Hawaii region. The numbers in the top right of the panels give the frequency of a TWI occurrence ("presence") and the 3-yr annual mean TWI height.

show a TWI in about $80 \%$ of the days (Cao et al. 2007). Zhang et al. (2012) show that the performance of the HRCM can be improved with higher model resolutions $(3 \mathrm{~km})$ as the topography of the Hawaiian Islands becomes better resolved than in our $15-\mathrm{km}$ experiments.

While not all RCP4.5 global warming experiments agree on the sign of the change in the days with a TWI and the TWI height, the RCP8.5 experiments show a robust increase in the TWI frequency and a robust decrease in the TWI height. The results from two-sample Kolmogorov-Smirnov tests (two sided) indicate that all PDFs shown in Fig. 8 for RCP4.5 and RCP8.5 differ statistically significantly from the PDF for present-day conditions at a confidence level of $99 \%$. For the RCP4.5 experiments, changes in the TWI frequency compared with the present-day simulation range between $-0.4 \%$ (MPI-ESM-LR) and 9.6\% (GISS-E2-R). Changes in the TWI height in the RCP4.5 experiments range between 12 (IPSL-CM5A-MR) and $-167 \mathrm{~m}$ (CSIRO-Mk3.6.0). All RCP8.5 experiments show an increase in the TWI frequency ranging between $1 \%$ (HadGEM2-ES) and $16.5 \%$ (GISS-E2-R) and a decrease in TWI height between 46 (HadGEM2-ES) and $355 \mathrm{~m}$ (CSIRO-Mk3.6.0). The model experiments using RCP4.5 and RCP8.5 multimodel mean warming increments lie in the middle of the range given by the model experiments using warming increments from individual CMIP5 models: increase in TWI frequency by $5.7 \%$ (RCP4.5) and $11.1 \%$ (RCP8.5); and decrease in TWI height by 52 (RCP4.5) and $157 \mathrm{~m}$ (RCP8.5). We find that the corresponding 

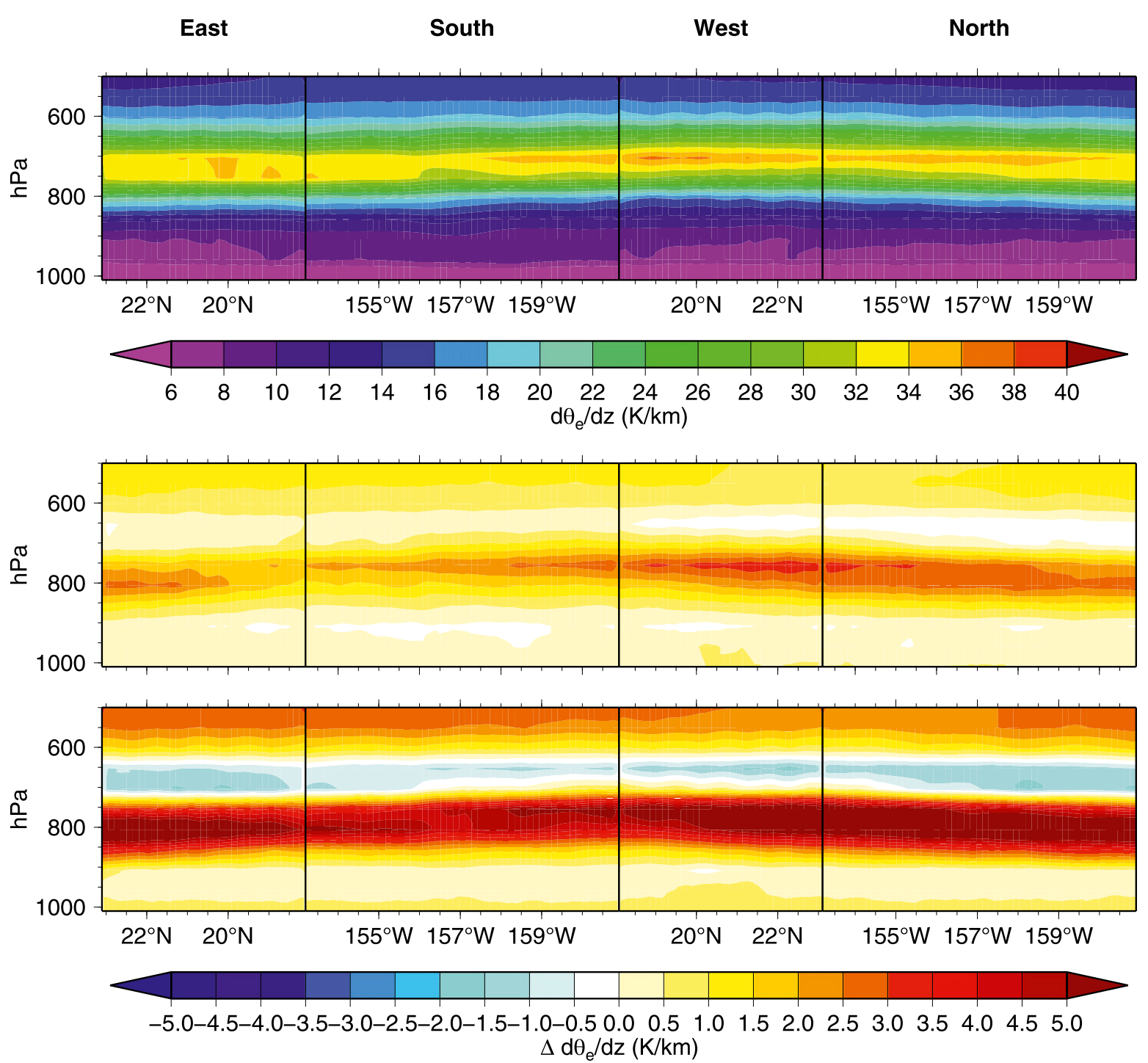

FIG. 9. Atmospheric stability along the lateral boundaries of the Hawaii region from left to right: east, south, west, and north. (top) The vertical gradient of the equivalent potential temperature $d \theta_{e} / d z$ for present-day conditions. Also shown are the projected changes in $d \theta_{e} / d z$ for the (middle) RCP4.5 and (bottom) RCP8.5 scenarios using multimodel mean warming increments.

average inversion strength in the RCP8.5 simulation increases by $0.5-1.0 \mathrm{~K}$ and the inversion thickness increases by about $30 \mathrm{~m}$. The vertical model resolution in the vicinity of the TWI is about $300 \mathrm{~m}$. All of the changes in TWI height and inversion thickness discussed above should be understood as changes in the average (mean) over the PDFs simulated for the different scenarios.

The decrease in TWI height found in the model experiments using RCP4.5 and RCP8.5 multimodel mean warming increments are consistent with changes in the atmospheric stability shown in Fig. 9. We calculate the mean atmospheric stability as the vertical gradient in equivalent potential temperature $\theta_{e}$,

$$
\frac{d \theta_{e}}{d z}=\frac{d}{d z}\left[T\left(1+\frac{L q_{e}}{c_{p} T}\right)\left(\frac{p}{p_{0}}\right)^{R / M_{d} c_{p}}\right],
$$

where $L$ is the latent heat of vaporization, $q_{e}$ is the specific humidity, $c_{p}$ is the heat specific capacity of dry air at constant pressure, $R$ is the universal gas constant, and $M_{d}$ is the molecular weight of dry air. The quantity $T$ is the temperature, $p$ is the ambient pressure, and $p_{0}$ is the reference pressure $(1000 \mathrm{hPa})$. In the present-day simulation, the maximum stability along the lateral boundaries of the Hawaii region is found in the height range of $750-700 \mathrm{hPa}$, slightly above the average TWI base height. The lower two rows of Fig. 9 show changes 
in the vertical equivalent potential temperature gradient for the RCP4.5 and RCP8.5 scenarios. In both scenarios, atmospheric stability is increased around the $800-\mathrm{hPa}$ level and decreased around the $700-\mathrm{hPa}$ level. This is consistent with the decrease in TWI base height in the two global warming scenarios over the Hawaii region. These changes in atmospheric stability are about twice as strong in the RCP8.5 scenario as in the RCP4.5 scenario. The general increase in atmospheric stability in the global warming experiments is a robust projection by current GCMs in a warmer climate. We would expect that this increased stability reduces the number of overshooting cumulus clouds penetrating into the inversion layer. The evaporation of such clouds in the dry and stable inversion layer tends to weaken the inversion and to raise the inversion layer (Riehl et al. 1951; Malkus 1958; Augstein et al. 1973). This suggests that a reduced number of clouds penetrating into the inversion layer would tend to strengthen the inversion and to lower the inversion height.

We would like to point out in particular that the static stability and the vertical structure of temperature, water vapor, and wind speed from the 15-km HRCM downscaling experiments along the lateral boundaries of the Hawaii region are significantly different from those derived directly from the CMIP5 multimodel mean results (see Fig. S5 of the supplementary material). In particular, the HRCM results show a higher and thus more realistic trade wind inversion. Even though most of the HRCM domain is covered with ocean grid cells, we expect more realistic results for simulations of climate in the Hawaii region using a nested downscaling approach than using the CMIP5 warming increments directly to drive, for instance, a 3-km nest over the Hawaiian Islands.

\section{e. 10-m wind speed and sea level pressure}

Figures 10 and 11 show the changes in the annual mean $10-\mathrm{m}$ wind speed $u_{10 \mathrm{~m}}$ for the RCP4.5 and RCP8.5 model experiments, respectively. As a reference, the changes in sea level pressure are shown in contours. Out of $10 \mathrm{RCP} 4.5$ model experiments using warming increments from individual CMIP5 models, 8 experiments project a decrease in the annual mean $u_{10 \mathrm{~m}}$ averaged over the Hawaii region and 2 experiments project an increase. Given that theoretical and multimodel ensembles project a reduction in the Walker circulation and a poleward expansion of the Hadley cell (Vecchi and Soden 2007, Ma et al. 2012), the decrease in the regional trade winds upstream of the islands is consistent with the general large-scale circulation changes. Results for the RCP4.5 scenario range between -0.43 and $0.16 \mathrm{~m} \mathrm{~s}^{-1}\left(-0.16 \mathrm{~m} \mathrm{~s}^{-1}\right.$ in the experiment with the multimodel mean warming increments). For RCP8.5, changes in the $10-\mathrm{m}$ wind speed range between -0.86 and
$0.34 \mathrm{~m} \mathrm{~s}^{-1}$ when averaged over the Hawaii region $\left(-0.18 \mathrm{~m} \mathrm{~s}^{-1}\right.$ in the experiment using the CMIP5 multimodel mean warming increments). Similarly, the geographical patterns of changes in mean 10-m wind speed in the Hawaii region show a large spread among the individual model experiments. Notably, the majority of the models project an increase in 10-m wind speed over the ocean facing the leeward (southwest) side of the Big Island, which is the only island that is resolved reasonably well in the $15-\mathrm{km}$ runs (Fig. 1). Besides this robust feature, the large spread among the individual model experiments gives only little confidence in the projected $10-\mathrm{m}$ wind speed changes in the Hawaii region. Model studies have demonstrated that regional wind changes strongly depend ${ }^{1}$ on the geographic pattern of the underlying SST anomalies (Gastineau et al. 2009; Ma et al. 2012). Subsequently, only the weakening of the Walker circulation appears as a robust feature, whereas changes in the strength and location of the subtropical high northeast of the Hawaiian Islands are not robust. It is however, the local position of the pressure gradients that determines the wind regime over Hawaii, which is known to be crucially important for the rainfall pattern in Hawaii (Lyons 1982; Timm and Diaz 2009). Zoomed versions of Figs. 10 and 11 showing the changes in 10-m wind speed over the main Hawaiian Islands in more detail are available in the supplementary material (Figs. S6 and S7).

The projected sea level pressure shows a large variability among the individual model simulations. The strength of the subtropical high located northeast of the Hawaiian Islands varies by about $2 \mathrm{hPa}$ among the individual experiments for the same warming scenario. The center of the subtropical high also varies significantly among the individual experiments. The subtropical high is on average $1-2 \mathrm{hPa}$ stronger in the RCP8.5 scenario than in the RCP4.5 scenario experiments.

\section{Multimodel mean and scalability between RCP4.5 and RCP8.5}

To quantify the variability in the downscaling results in the experiments using warming increments from individual CMIP5 models, we calculate interexperiment mean and standard deviation. Figures 12 and 13 show comparisons of the downscaling results obtained from experiments using the CMIP5 multimodel mean warming increments with the average over the results obtained from the 10 downscaling experiments using warming increments from individual CMIP5 models. Depicted are results for changes in 2-m temperatures, rainfall (relative

\footnotetext{
${ }^{1}$ Wind and SST anomalies are tightly coupled and the ultimate cause for SST pattern anomalies is a complex problem (Xie et al. 2010; Tokinaga et al. 2012).
} 

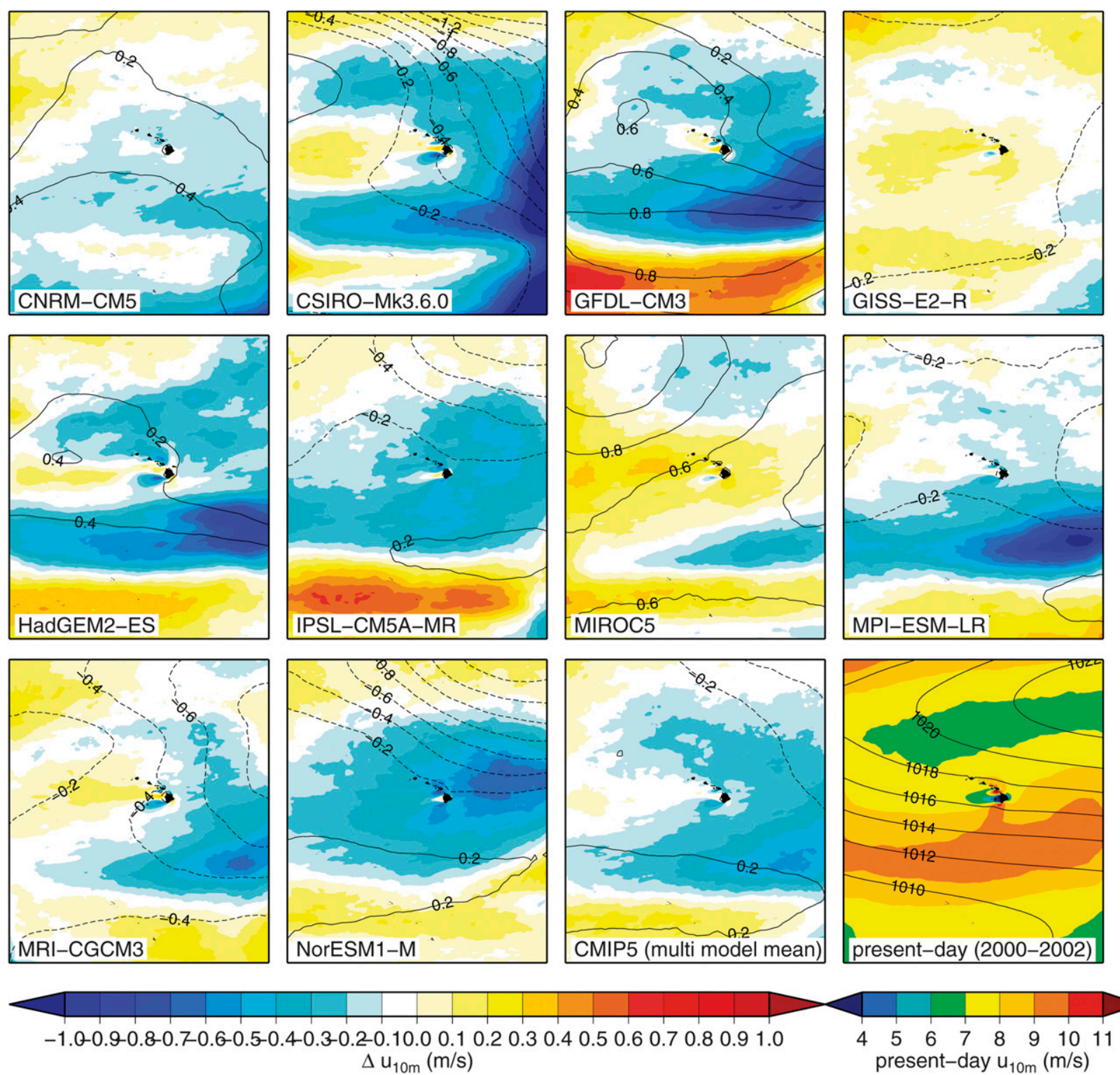

FIG. 10. As in Fig. 6, but for the 10-m wind speed (color shades) and the annual mean sea level pressure (hPa, contours).

changes $=\Delta$ rain $_{\text {future }}\left(\right.$ rain $\left._{\text {present-day }}\right)$, and $10-\mathrm{m}$ wind speed for RCP4.5 and RCP8.5 warming increments, respectively. The interexperiment spread is estimated as the standard deviation of the experiment ensemble using warming increments from individual CMIP5 models. Despite the large spread in downscaling results particularly in relative precipitation changes and $10-\mathrm{m}$ wind speed, the geographical patterns and amplitudes of the results from the experiment using multimodel mean warming increments and from the ensemble mean of the experiments using warming increments from individual CMIP5 models are remarkably similar. While this could be expected for the changes in 2-m temperatures as they are largely determined by the prescribed warming in SST, this is surprisingly the case for precipitation and 10-m wind speed as well. These findings for dynamical downscaling in the Hawaii region using CMIP5 results are similar to the ones reported by Kawase et al. (2009) for the baiu rainband in East Asia. Kawase et al. (2009) found that dynamical downscaling with the PGW method using warming increments from selected CMIP3 models gives similar results when averaged over experiments using warming increments from individual models compared with the experiment using multimodel mean warming increments. This similarity between the ensemble average of experiments using warming increments from 

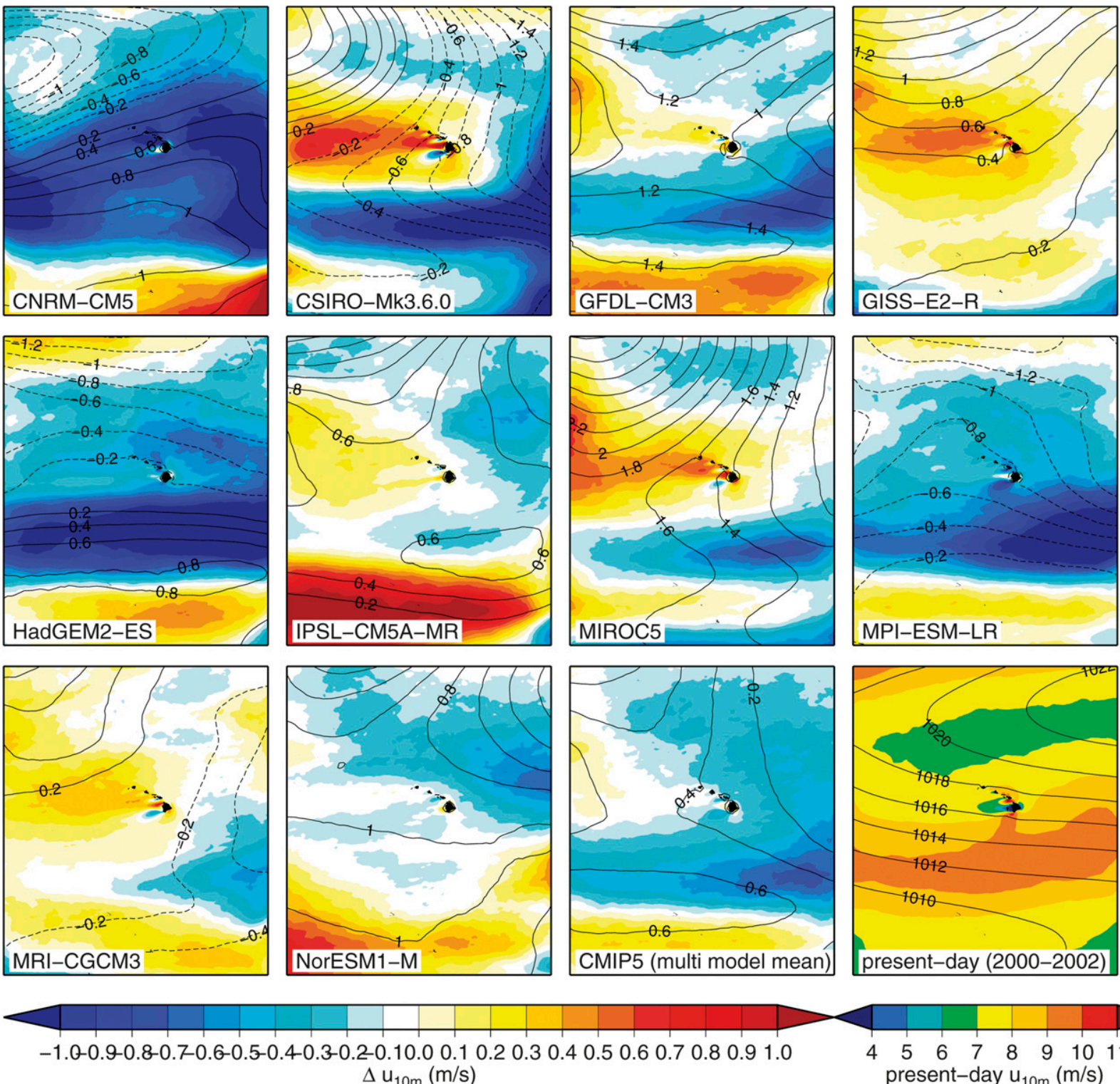

$\begin{array}{llllllll}4 & 5 & 6 & 7 & 8 & 9 & 10 & 11\end{array}$

FIG. 11. As in Fig. 10, but for the RCP8.5 scenario.

individual models and results from the experiment using multimodel mean warming increments translates into high linear pattern correlations of changes in 2-m temperature and $10-\mathrm{m}$ wind speed and precipitation between the two downscaling datasets. For 2-m temperature, the linear pattern correlation of the annual mean changes from the two datasets is 0.99 (RCP4.5 and RCP8.5); for $10-\mathrm{m}$ wind speed, it is 0.98 (RCP4.5 and RCP8.5); and, for relative changes in rainfall, it is 0.74 (RCP4.5) and 0.90 (RCP8.5).

We also find some similarity in the geographical patterns of changes in 2-m temperature, $10-\mathrm{m}$ wind speed, and rainfall in experiments for RCP4.5 and RCP8.5. The spatial correlation coefficients of the response of $2-\mathrm{m}$ temperature, 10-m wind speed, and rainfall between RCP4.5 and RCP8.5 experiments for the four seasons [December-February (DJF), March-May (MAM), JuneAugust (JJA), and September-November (SON)] and for annual mean changes (YR) are shown in Fig. 14. Also shown are the correlation coefficients for the prescribed SST warming increments between the RCP4.5 and RCP8.5 experiments. As expected for a model domain mostly covered by ocean, the correlations in 2-m temperature changes follow very closely the correlations in prescribed SST warming. While the spatial correlation between changes in 2-m temperature for RCP4.5 and RCP8.5 vary widely among the experiments using 

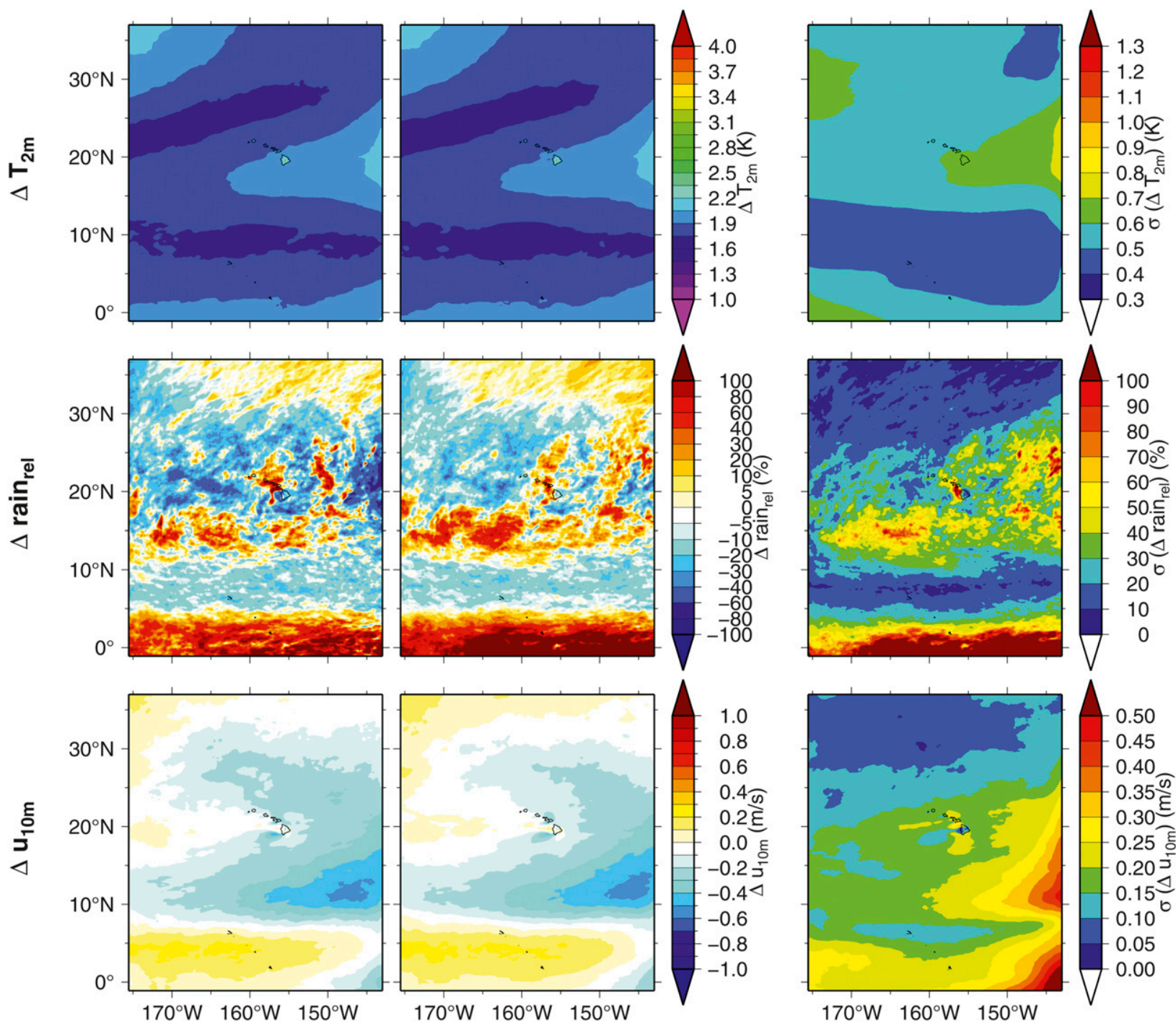

FIG. 12. Changes in (top) annual mean $T_{2 \mathrm{~m}}$, (middle) rainfall (relative changes), and (bottom) $u_{10 \mathrm{~m}}$ for the RCP4.5 scenario averaged over 3 years. (left) Results from the model experiment using the CMIP5 multimodel mean warming increments. (center) The average over all model experiments with warming increments from individual CMIP5 models. (right) The interexperiment standard deviation of these model runs.

warming increments from individual CMIP5 models (individual seasons: from -0.23 to 0.97 ; annual mean: 0.12-0.95), correlations are high for the experiment using multimodel mean warming increments (individual seasons: 0.87-0.96; annual mean: 0.88).

Annual mean changes in $u_{10 \mathrm{~m}}$ from experiments using multimodel mean warming increments for RCP4.5 and RCP8.5 are also highly correlated (correlation coefficient $=0.92$ ). This is also the case for individual seasons with correlation coefficients for the experiments using multimodel mean warming increments ranging between 0.81 (DJF) and 0.93 (SON).

For relative changes in precipitation, the geographical pattern correlations between RCP4.5 and RCP8.5 results are much smaller than for those in 10-m wind speed and 2-m temperature in most of the experiments using warming increments from individual models. This is also the case for the experiments using multimodel mean warming increments for individual seasons. Here, correlation coefficients range between 0.02 (JJA) and 0.92 (MAM). For annual mean relative changes in precipitation, however, the correlation coefficient between RCP4.5 and RCP8.5 from the experiments using multimodel mean warming increments is roughly as high as for 2-m temperature and 10-m wind speed (0.95). Our results suggest that experiments with the PGW method using multimodel mean warming increments give rather similar geographical patterns for RCP4.5 and RCP8.5 warming 

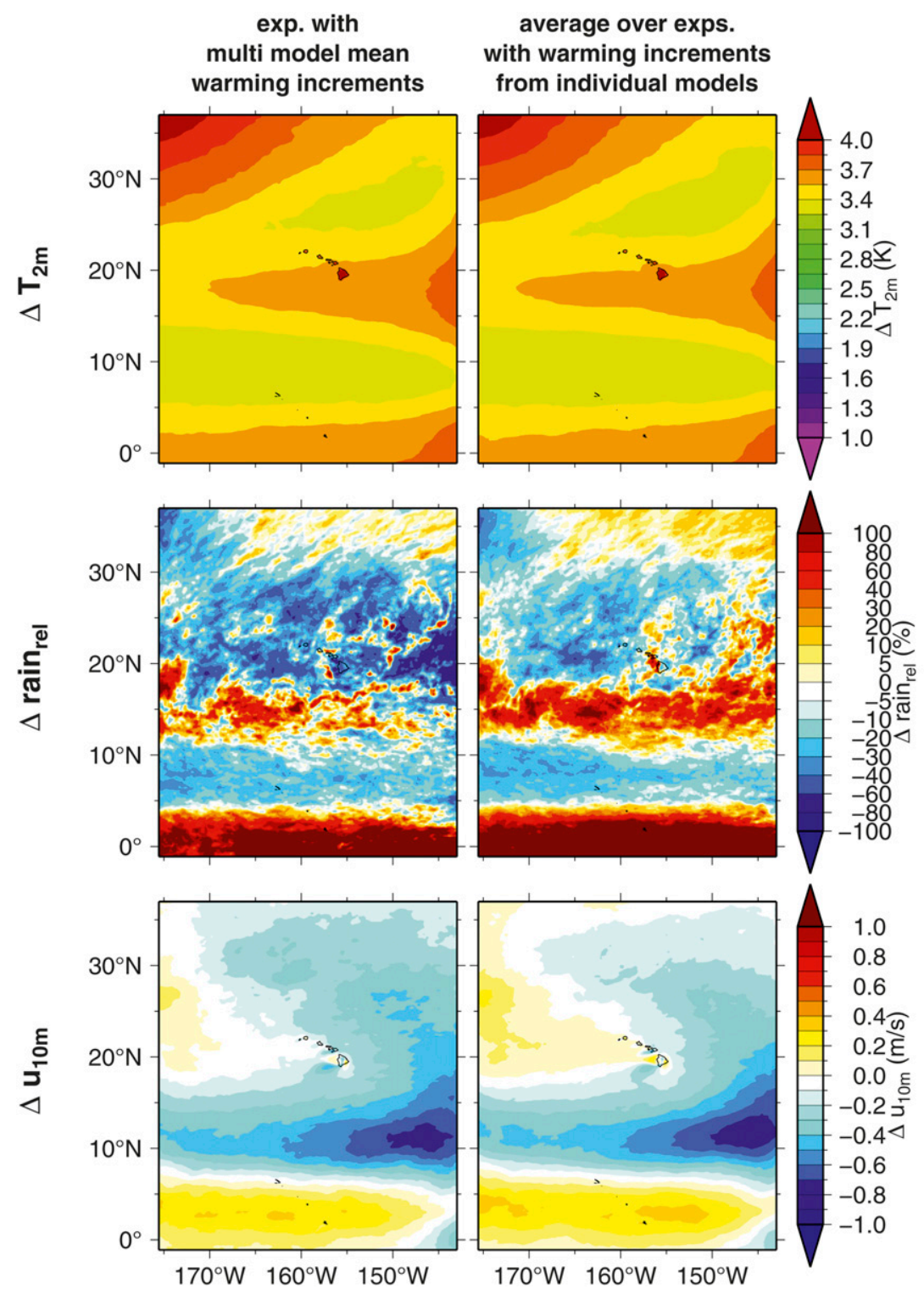

std. dev. of exps.
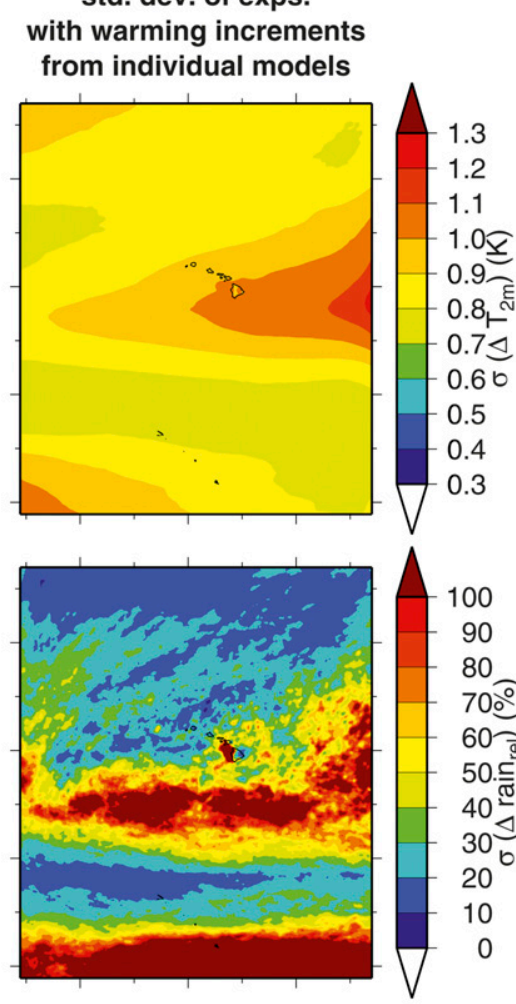

100

90

80

$70 \%$

60 \%

$50 . \frac{\text { त. }}{4}$

40 뉴

$30 \frac{\triangleleft}{6}$

20

10

0

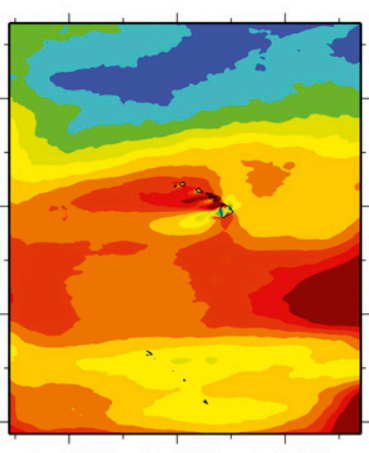

$170^{\circ} \mathrm{W} \quad 160^{\circ} \mathrm{W} \quad 150^{\circ} \mathrm{W}$

FIG. 13. As Fig. 12, but for the RCP8.5 scenario.

increments when considering annual mean changes in 2-m temperature, $10-\mathrm{m}$ wind speed, and rainfall in the Hawaii region.

As discussed in our introduction our intention is to conduct PGW experiments with HRCM configured with nested grids over the Hawaii region with resolutions much finer than $15 \mathrm{~km}$. This raises the question to which degree the atmospheric variables along the lateral boundaries of the Hawaii region in the experiments discussed here are similar to (i) an experiment using the multimodel mean warming increments or (ii) averaging over all experiments using warming increments from individual CMIP5 models.
Figures 15 and 16 show the vertical profiles of temperature, specific humidity, and zonal wind along the lateral boundaries of the Hawaii region. Shown are results from the $15-\mathrm{km}$ simulations using multimodel mean warming increments in comparison with results averaged over all 10 model experiments using warming increments from individual CMIP5 models. Figure 15 shows anomalies in temperature, specific humidity, and zonal wind for the RCP4.5 scenario relative to the presentday simulation, and Fig. 16 shows the anomalies for RCP8.5. In both the RCP4.5 and RCP 8.5 cases, the vertical structure and the amplitude of the annual mean anomalies along the lateral boundaries are almost identical. 

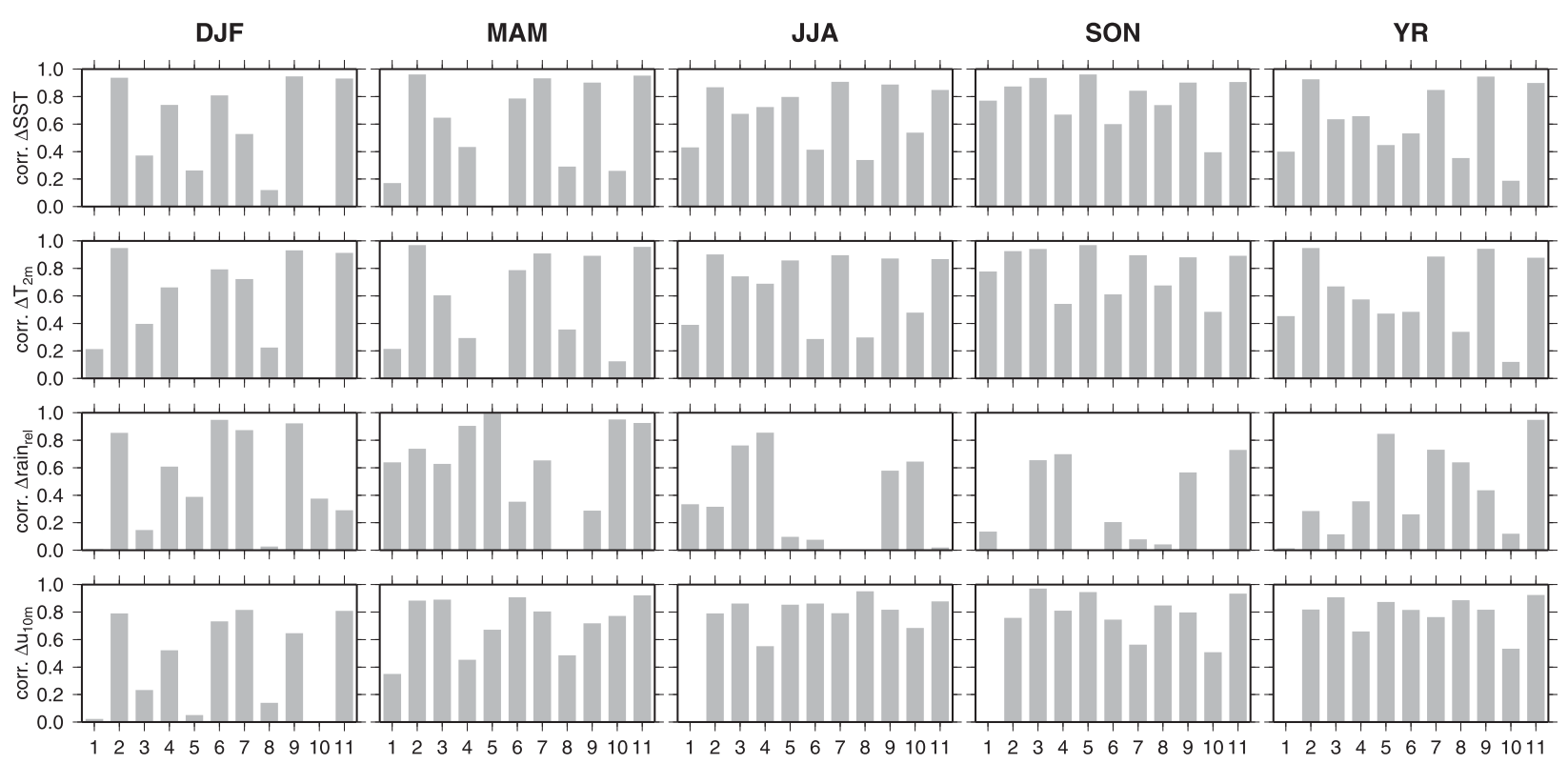

\begin{tabular}{|llll|}
\hline & & Warming increments \\
& & & \\
1 CNRM-CM5 & 2 CSIRO-Mk3.6.0 & 3 GFDL-CM3 & 4 GISS-E2-R \\
5 HadGEM2-ES & 6 IPSL-CM5A-MR & 7 MIROC5 & 8 MPI-ESM-LR \\
9 MRI-CGCM3 & 10 NorESM1-M & 11 CMIP5 multi model mean & \\
\hline
\end{tabular}

FIG. 14. Linear pattern correlations of the 3-yr seasonal mean changes in (top to bottom) SST, 2-m temperature, rainfall (relative changes), and 10-m wind speed between model experiments using RCP4.5 and RCP8.5 warming increments. The four columns show the individual seasons from left to right: winter (DJF), spring (MAM), summer (JJA), fall (SON), and annual mean (YR).

The high spatial correlation in the geographical pattern of annual mean changes in 2-m temperature, $10-\mathrm{m}$ wind speed, and rainfall for RCP4.5 and RCP8.5 downscaling experiments raises the question to which degree the results from these two warming scenarios may be scalable in terms of a characteristic mean warming. To investigate the scalability of the results, we calculate the ratio between changes in 2-m temperature, $10-\mathrm{m}$ wind speed, and rainfall from the RCP4.5 experiment and the RCP8.5 experiment using multimodel mean warming increments (Fig. 17). For each grid cell, the ratios $r_{x}$ of quantity $x$ ( $x$ can be $T_{2 \mathrm{~m}}, u_{10 \mathrm{~m}}$, and rainfall) have been normalized by changes in surface temperature $\Delta T_{\text {sfc }}$,

$$
r_{x}=\frac{\Delta x_{\mathrm{RCP} 8.5}}{\Delta x_{\mathrm{RCP} 4.5}} \times \frac{\Delta T_{\mathrm{sfc} \mid \mathrm{RCP} 4.5}}{\Delta T_{\mathrm{sfc} \mid \mathrm{RCP} 8.5}} .
$$

Note that, in Fig. 17, grid cells with changes in 10-m wind speed of less than $0.05 \mathrm{~m} \mathrm{~s}^{-1}$ and in rain of less than $10 \%$ have been masked out.

Changes in 2-m temperatures for RCP4.5 and RCP8.5 show an almost uniform ratio throughout the model domain, suggesting a high scalability between the two warming scenarios. Averaged over the whole model domain, the normalized ratio of changes in 2-m temperature between RCP 8.5 and RCP4.5 is 1.0 with a spatial standard deviation of 0.01 . The reason for this high scalability (i.e., almost a uniform ratio of RCP8.5 to RCP4.5 throughout the domain) is the strong dependence of 2-m temperature on SST. As the SST warming patterns in the multimodel mean warming increments are smoothed compared with the warming increments from individual models, a high scalability can be expected from the prescribed almost uniform SST warming. In contrast to $2-\mathrm{m}$ temperature, the RCP8.5 to RCP4.5 ratio for rainfall shows a strongly heterogeneous spatial distribution. The stochastic nature of convective precipitation reduces the signal to noise ratio for changes in rainfall, clearly showing the limitations of 3-yr integrations for projected changes in such a quantity. The domain average normalized ratio of RCP8.5 to RCP4.5 for relative rainfall changes is 0.80 with a spatial standard deviation of 1.13. The scalability of changes in $10-\mathrm{m}$ wind speed lies in between those of $2-\mathrm{m}$ temperature and rainfall. The domain average normalized ratio of $10-\mathrm{m}$ wind speed between RCP8.5 and RCP4.5 is 0.83 with a spatial standard deviation of 0.42 . Our results for 

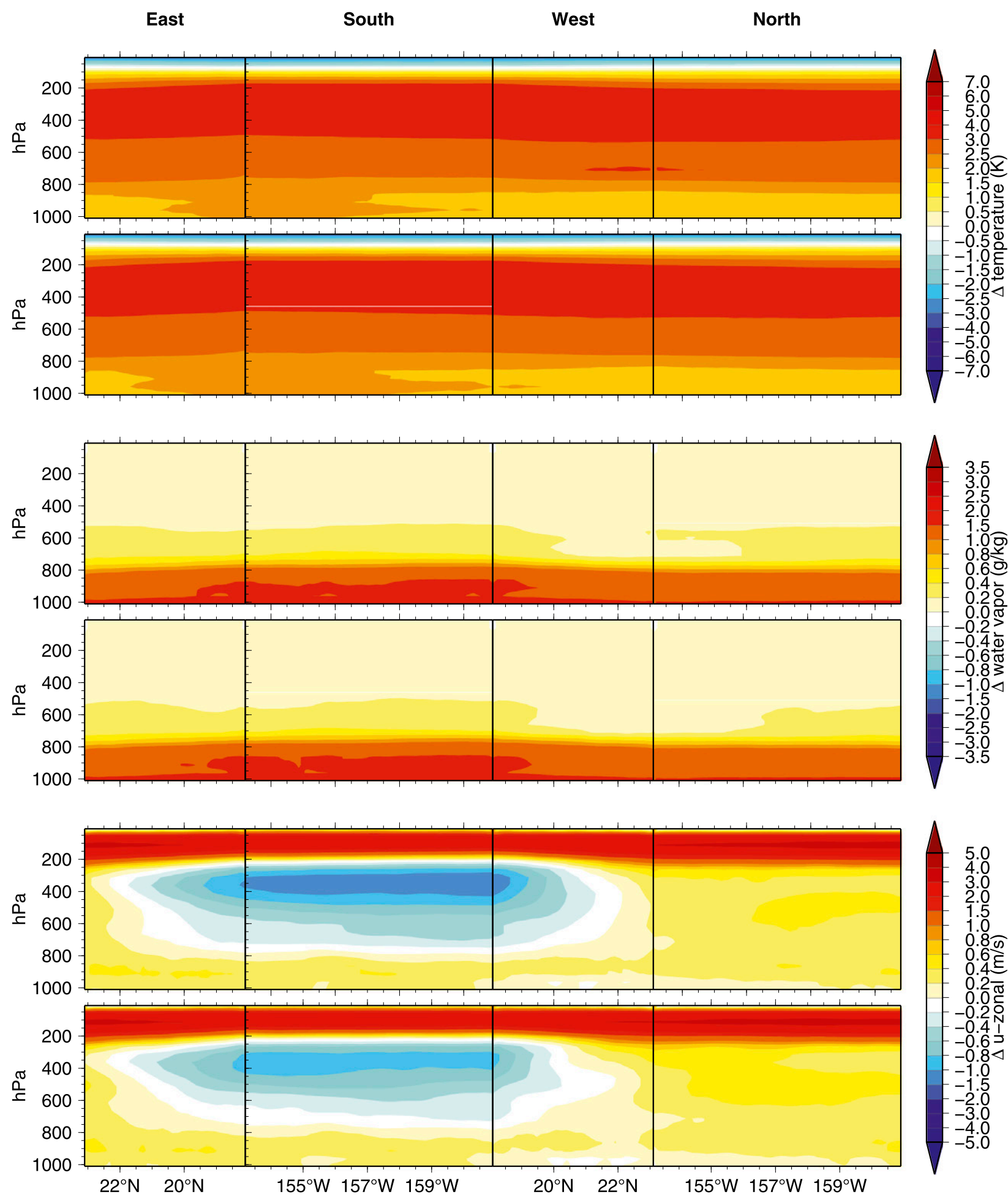

FIG. 15. Differences in (top) annual mean temperature, (middle) water vapor mixing ratio, and (bottom) zonal wind between presentday conditions and projections for the RCP4.5 scenario along the lateral boundaries of the Hawaii region from left to right: east, south, west, and north. The upper rows of each variable are averaged over all 10 experiments using warming increments from individual CMIP5 models, and the lower rows are from the experiment using multimodel mean warming increments. 

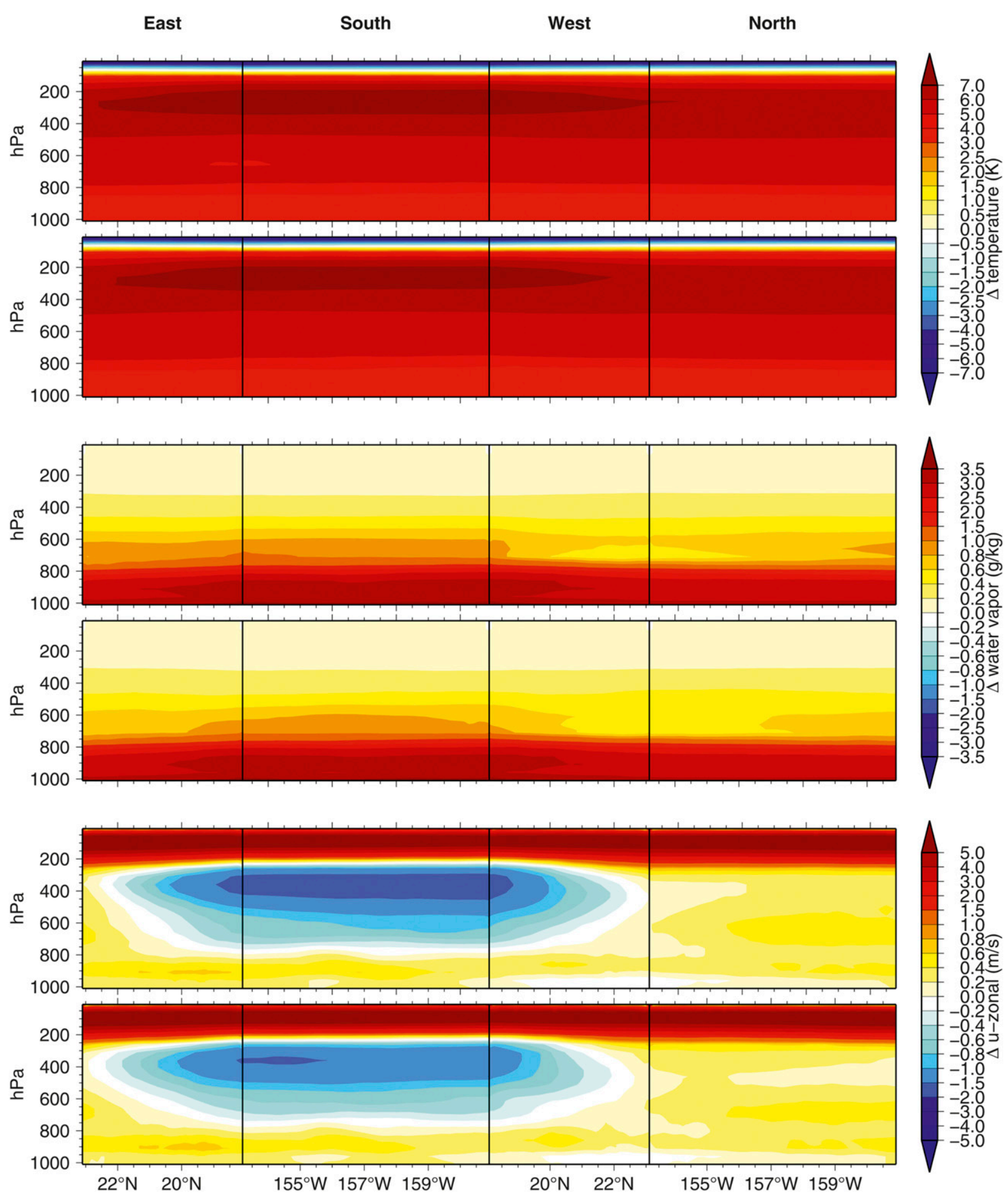

FIG. 16. As in Fig. 15, but for the RCP8.5 scenario.

dynamical downscaling in the Hawaii region with the PGW method using multimodel mean warming increments for RCP4.5 and RCP8.5 suggest that local 2-m temperature changes can be estimated by applying simple scaling factors rather than expensive additional simulations for different warming scenarios. However, the linear scaling breaks down to some extent for the changes in $10-\mathrm{m}$ wind speed and rainfall. 

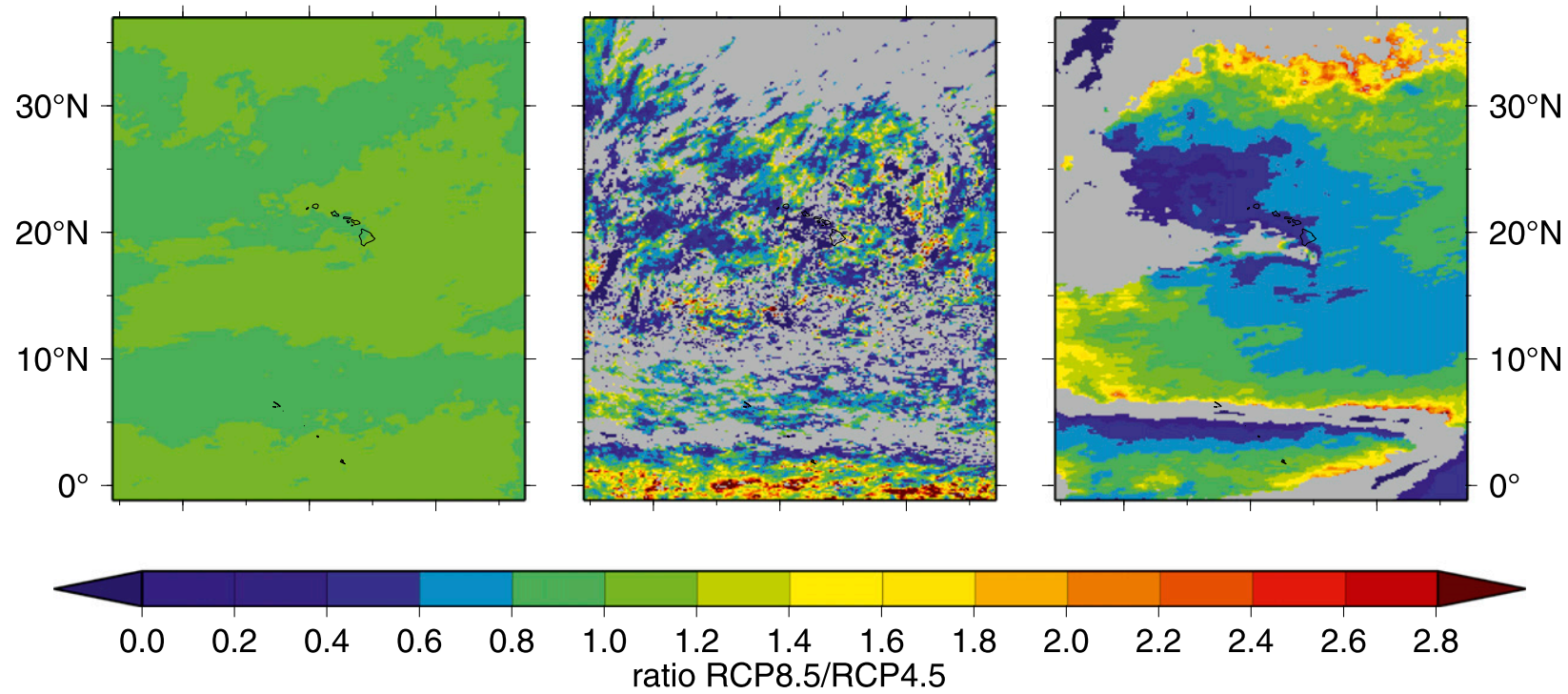

FIG. 17. Ratio of annual mean changes in (left)-(right) 2-m temperature, rainfall (relative changes), and 10-m wind speed for RCP8.5 and RCP4.5 model experiments normalized by their corresponding surface warming. The ratios shown are calculated from model experiments using multimodel mean warming increments. Gray shading shows regions with only small changes between the warming experiments and present-day results (changes in wind speed $<0.05 \mathrm{~m} \mathrm{~s}^{-1}$ and in rainfall $<10 \%$ of the present-day values).

\section{Summary and conclusions}

Dynamical downscaling of results from global oceanatmosphere models with a regional climate model for a limited area domain is a promising approach to obtain the high-resolution data needed to assess climate change on regional and local scales. The initial and in particular the lateral boundary conditions provided to the regional model are of great importance as they determine a significant source of uncertainties in the downscaling results.

We have conducted calculations to address some of these issues relevant to downscaling of global climate model warming projections in the Hawaii region. In contrast to the regions considered in most earlier downscaling experiments, our area of interest is characterized by almost total ocean coverage that is interrupted by small islands with very high and steep topography. The downscaling problem in this region is also affected by a synoptic regime dominated by trade winds near the surface and characteristic trade wind boundary layer structure. We applied a regional atmospheric model covering a roughly $4000 \times 4000 \mathrm{~km}^{2}$ region with a horizontal grid spacing of $15 \mathrm{~km}$. This horizontal grid is not fine enough to resolve the microclimates over the individual Hawaiian Islands, but we have examined the projected changes for key variables that we expect will largely determine the local scale climate: notably, 2-m temperature, $10-\mathrm{m}$ wind speed, rainfall, water vapor path, and TWI height and strength. Our calculations have been performed using the PGW framework and each projection requires specification of warming increments based on results from global coupled models. We attempted to understand the dependence of the regional projection on the global model results used, and we conducted experiments with warming increments from 10 individual CMIP5 models and for two warming scenarios from the CMIP5 suite of experiments (RCP4.5 and RCP8.5).

The global models selected for this study vary significantly in the magnitude and pattern of projected surface warming and one key question is how this variation is reflected in the regional model results for different variables. For example, in each model projection the changes in mean rainfall have a fairly complicated geographical pattern with large areas of both higher and lower rainfall apparent. Among the models the projected rainfall change patterns have some robust features such as increases in the ITCZ and decreases in a band north of the ITCZ, but the projected changes near the Hawaiian Islands vary quite substantially among the models used for the warming increments. The interexperiment spread in the projected values of other variables such as $10-\mathrm{m}$ wind speed, water vapor path, and TWI height is also substantial.

In the PGW approach the boundary conditions (including SSTs) are specified based on present-day observations together with warming increments based on a global model projection of changes in the mean climate. While this constrains how the regional model may behave, we did find interesting responses in the regional 
model even for surface air temperatures, at least over the land points in the Hawaiian Islands. While reflecting the overall imposed SST warming, we found that the shape of the PDF of daily mean temperatures over the land changes significantly, generally becoming broader in the warmer climate. The simulated liquid water path in the Hawaii region was also found to increase in response to the imposed warming, and the day-to-day variability also generally increased. The changes seen in the PDFs of daily values depend strongly on the global model used to define the imposed warming increments.

In the analysis of global model climate projections one approach to dealing with the variability of the results among different global models forced identically has been to simply compute a multimodel mean. This is potentially problematic for very-fine-resolution downscaled climate projections for which the computational effort to downscale many separate global model projections might be prohibitive. In this study, we investigated the viability of a single downscaled PGW projection based on the imposition of a multimodel mean of the imposed warming increments. We found that the projected global warming induced changes in the annual mean values of surface air temperature, surface wind, and rainfall in an experiment forced with a multimodel mean warming increment are very close to the mean of the changes found over experiments in which the warming increment from each of the models was applied. This is the case for both warming scenarios investigated here: namely, RCP4.5 and RCP8.5. Our result is consistent with earlier findings for East Asia by Kawase et al. (2009), who showed that average results from downscaling experiments with the PGW method using warming increments from selected CMIP3 models give similar results to one experiment using multimodel mean warming increments. It is interesting that this result is found both in the experiments for East Asia, where the global model warming increments on the lateral boundaries presumably largely force the response in the regional model, and in the Hawaii region, which is mainly ocean covered and strongly affected by the imposed SST increments taken from the global models.

We note that that the inferred changes in variance and extreme statistics are more sensitive, and single forcing experiments with multimodel ensemble warming increments may be less representative than the repeated downscaling experiments with multiple warming scenarios. The similarity between the results for the experiments using multimodel mean warming increments and results averaged over all experiments using warming increments from individual CMIP5 models is also found in the variables surrounding a smaller area in the Hawaii region that has been planned as the region for a higher- resolution nested downscaling. We have shown that the vertical structure and the amplitude of the annual mean anomalies in relevant variables along the proposed fine grid lateral boundaries are almost identical for both approaches.

Current expectations are that the Earth system will be subject to a climate forcing dominated by the effects of increased concentrations of long-lived greenhouse gases over the next century. Standard climate forcing scenarios such as those used in CMIP5 typically vary more in the magnitude of the forcing imposed at any time than in the geographical patterns. Earlier work (e.g., Solomon et al. 2007, section 10.3.2.1) has shown that the projected surface warming seen in global coupled models can be very approximately described by a fixed geographical pattern modulated by a mean warming. The mean warming, of course, increases over time but also depends on the forcing scenario adopted. Here we used our higherresolution downscaled results to see how well such a simple scaling of the response on the mean warming applies in our experiments (including other variables in addition to the temperature). In particular we compared the responses in the RCP4.5 and RCP8.5 cases for several variables in both individual models and in the multimodel mean forced experiments. We found that, while the linear pattern correlations between results for RCP4.5 and RCP8.5 using warming increments from individual CMIP5 models vary significantly among the experiments, seasons, and variables, the pattern correlations are high for annual average changes in 2-m temperature, $10-\mathrm{m}$ wind speed, and rainfall in the experiments using multimodel mean warming increments.

Computational limitations led us to restrict each of our simulations to only 3 years. The limited sampling affects, for example, our determination of how local global warming-induced rainfall changes may scale with the mean surface warming, but we feel that the basic conclusion of our paper is robust: namely, that one downscaling experiment with the PGW method in the Hawaii region using multimodel mean warming increments will produce results close to the ensemble mean of multiple experiments with the warming increments from individual models. In addition, the results seem also to suggest that the internal variability of the projected changes may not be solely determined by the variability provided through the lateral boundary forcing. The limitation of the PGW method that changes in the synoptic variability of the lateral boundary forcing fields between present-day and the future climate cannot be represented could therefore be acceptable for this kind of downscaling application. This idea is also supported by the large uncertainties in the synoptic and interannual variabilities in current stateof-the-art global atmosphere-ocean model simulations. 
This work has helped us formulate the execution and analysis of finer-resolution doubly nested and triply nested regional model climate downscaling experiments for the Hawaii region that are now underway.

Acknowledgments. This research was supported by NASA through Grant NNX07AG53G; NOAA through Grant NA09OAR4320075; and by the Japan Agency for Marine-Earth Science and Technology (JAMSTEC), which sponsors research at the International Pacific Research Center. We acknowledge support as well from USGS Grant G12AC20501, U.S. Fish and Wildlife Service Grant 12200-A-J022, and the NOAA/Pacific Regional Integrated Science and Assessment Program via subcontract HC12761 from the East-West Center. We acknowledge the World Climate Research Programme's Working Group on Coupled Modelling, which is responsible for CMIP, and we thank the climate modeling groups (listed in Table 3 of this paper) for producing and making available their model output. For CMIP, the U.S. Department of Energy's Program for Climate Model Diagnosis and Intercomparison provides coordinating support and led development of software infrastructure in partnership with the Global Organization for Earth System Science Portals. All model simulations with the Hawaii Regional Climate Model were performed at the Hawaii Open Supercomputing Center (HOSC).

\section{REFERENCES}

Augstein, A., H. Reihl, F. Ostapoff, and V. Wagner, 1973: Mass and energy transports in an undisturbed Atlantic trade wind flow. Mon. Wea. Rev., 101, 101-111.

Buytaert, W., R. Celleri, and L. Timbe, 2009: Predicting climate change impacts on water resources in the tropical Andes: Effects of GCM uncertainty. Geophys. Res. Lett., 36, L07406, doi:10.1029/2008GL037048.

Cao, G., T. Giambelluca, D. E. Stevens, and T. A. Schroeder, 2007: Inversion variability in the Hawaiian trade wind regime. J. Climate, 20, 1145-1160.

Chu, P.-S., and H. Chen, 2005: Interannual and interdecadal rainfall variations in the Hawaiian Islands. J. Climate, 18, 47964813.

Collins, M., and Coauthors, 2010: The impact of global warming on the tropical Pacific Ocean and El Niño. Nat. Geosci., 3, 391397, doi:10.1038/ngeo868

Collins, W. J., and Coauthors, 2011: Development and evaluation of an Earth-system model-HadGEM2. Geosci. Model Dev., 4, 1051-1075, doi:10.5194/gmd-4-1051-2011.

Dee, D. P., and Coauthors, 2011: The ERA-Interim reanalysis: Configuration and performance of the data assimilation system. Quart. J. Roy. Meteor. Soc., 137, 553-597.

Diniz Filho, J. A. F., L. M. Bini, T. F. Rangel, R. D. Loyola, C. Hof, D. Nogués-Bravo, and M. B. Araújo, 2009: Partitioning and mapping uncertainties in ensembles of forecasts of species turnover under climate change. Ecography, 32, 897-906.

Donner, L. J., and Coauthors, 2011: The dynamical core, physical parameterizations, and basic simulation characteristics of the atmospheric component AM3 of the GFDL global coupled model CM3. J. Climate, 24, 3483-3519.

Dufresne, J.-L., and Coauthors, 2013: Climate change projections using the IPSL-CM5 Earth System Model: From CMIP3 to CMIP5. Climate Dyn., 40, 212-2165, doi:10.1007/ s00382-012-1636-1.

Foley, A. M., 2010: Uncertainty in regional climate modeling: A review. Prog. Phys. Geogr., 34, 647-670, doi:10.1177/ 0309133310375654

Gastineau, G., L. Li, and H. Le Treut, 2009: The Hadley and Walker circulation changes in global warming conditions described by idealized atmospheric simulations. J. Climate, 22, 3993-4013.

Giambelluca, T. W., and M. A. Schroeder, 1986: Rainfall atlas of Hawaii. Department of Land and Natural Resources Hawaii Rep. R76, 267 pp.

- and D. Nullet, 1991: Influence of the trade-wind inversion on the climate of a leeward mountain slope in Hawaii. Climate Res., 1, 207-216, doi:10.3354/cr001207.

Kawase, H., T. Yoshikane, M. Hara, F. Kimura, T. Yasunari, B. Ailikun, H. Ueda, and T. Inoue, 2009: Intermodel variability of future changes in the baiu rainband estimated by the pseudo global warming downscaling method. J. Geophys. Res., 114, D21110, doi:10.1029/2009JD011803.

Kay, A. L., H. N. Davies, V. A. Bell, and R. G. Jones, 2009: Comparison of uncertainty sources for climate change impacts: Flood frequency in England. Climatic Change, 92, 4163.

Khairoutdinov, M., and Y. Kogan, 2000: A new cloud physics parameterization in a large-eddy simulation model of marine stratocumulus. Mon. Wea. Rev., 128, 229-243.

Kimura, F., and A. Kitoh, 2007: Downscaling by pseudo-globalwarming method. The Final Report of the ICCAP, RIHN Project 1-1, 43-46.

Kirkevåg, A., and Coauthors, 2013: Aerosol-climate interactions in the Norwegian Earth System Model - NorESM1-M. Geosci. Model Dev., 6, 207-244, doi:10.5194/gmd-6-207-2013.

Knutsen, T. R., J. J. Sirutus, S. T. Garner, G. A. Vecchi, and I. M. Held, 2008: Simulated reduction in Atlantic hurricane frequency under twenty-first century warming conditions. Nat. Geosci., 1, 359-364.

Lyons, S. W., 1982: Empirical orthogonal function analysis of Hawaiian rainfall. J. Appl. Meteor., 21, 1713-1729.

Ma, J., S.-P. Xie, and Y. Kosaka, 2012: Mechanisms for tropical tropospheric circulation change in response to global warming. J. Climate, 25, 2979-2994.

Malkus, J. S., 1958: On the structure of the trade wind moist layer. Massachusetts Institute of Technology and Woods Hole Oceanographic Institution Papers in Physical Oceanography and Meteorology, Vol. 13, No. 2, 47 pp.

Meehl, G. A., C. Covey, T. Delworth, M. Latif, B. McAvaney, J. F. B. Mitchell, R. J. Stouffer, and K. E. Taylor, 2007: The WCRP CMIP3 multimodel dataset: A new era in climate change research. Bull. Amer. Meteor. Soc., 88, 1383-1394.

Reynolds, R. W., T. M. Smith, C. Liu, D. B. Chelton, K. S. Casey, and M. S. Schlax, 2007: Daily high-resolution-blended analyses for sea surface temperature. J. Climate, 20, 5473-5496.

Riehl, H., T. C. Yeh, J. S. Malkus, and N. E. La Seur, 1951: The northeast trade of the Pacific Ocean. Quart. J. Roy. Meteor. Soc., 77, 598-626.

Rienecker, M. M., and Coauthors, 2011: MERRA: NASA's Modern-Era Retrospective Analysis for Research and Applications. J. Climate, 24, 3624-3648. 
Roeckner, E., and Coauthors, 2006: Sensitivity of simulated climate to horizontal and vertical resolution in the ECHAM5 atmosphere model. J. Climate, 19, 3771-3791.

Rotstayn, L. D., M. A. Collier, M. R. Dix, Y. Feng, H. B. Gordon, S. P. O'Farrell, I. N. Smith, and J. Syktus, 2010: Improved simulation of Australian climate and ENSO-related climate variability in a GCM with an interactive aerosol treatment. Int. J. Climatol., 30, 1067-1088, doi:10.1002/joc.1952.

Rummukainen, M., 2010: State-of-the-art with regional climate models. Wiley Interdiscip. Rev. Climate Change, 1, 82-96, doi:10.1002/wcc.8.

Sato, T., F. Kimura, and A. Kitoh, 2007: Projection of global warming onto regional precipitation over Mongolia using a regional climate model. J. Hydrol., 333, 144-154.

Schmidt, G. A., and Coauthors, 2006: Present-day atmospheric simulations using GISS ModelE: Comparison to in situ, satellite, and reanalysis data. J. Climate, 19, 153-192.

Skamarock, W. C., J. B. Klemp, J. Dudhia, D. O. Gill, D. M. Barker, W. Wang, and J. G. Powers, 2008: A description of the Advanced Research WRF version 3. NCAR Tech. Note NCAR-TN-475+STR, 113 pp.

Solomon, S., D. Qin, M. Manning, M. Marquis, K. Averyt, M. M. B. Tignor, H. L. Miller, and Z. Chen, Eds., 2007: Climate Change 2007: The Physical Science Basis. Cambridge University Press, 996 pp.

Taylor, K. E., R. Stouffer, and G. A. Meehl, 2012: An overview of CMIP5 and the experiment design. Bull. Amer. Meteor. Soc., 93, 485-498.

Timm, O., and H. F. Diaz, 2009: Synoptic-statistical approach to regional downscaling of IPCC twenty-first-century climate projections: Seasonal rainfall over the Hawaiian Islands. J. Climate, 22, 4261-4280.

Tokinaga, H., S.-P. Xie, A. Timmermann, S. McGregor, T. Ogata, H. Kubota, and Y. M. Okumura, 2012: Regional patterns of tropical Indo-Pacific climate change: Evidence of the Walker circulation weakening. J. Climate, 25, 1689-1710.

Vecchi, G., and B. J. Soden, 2007: Global warming and the weakening of the tropical circulation. J. Climate, 20, 4316-4340.

, and A. Wittenberg, 2010: El Niño and our future climate: Where do we stand? Wiley Interdiscip. Rev. Climate Change, 1, 260-270.
Voldoire, A., and Coauthors, 2011: The CNRM-CM5.1 global climate model: Description and basic evaluation. Climate Dyn., 25, 1689-1710, doi:10.1007/s00382-011-1259-y.

Wang, B., and H. Yang, 2008: Hydrological issues in lateral boundary conditions for regional climate modeling: Simulation of East Asian summer monsoon in 1998. Climate Dyn., 31, 477-490, doi:10.1007/s00382-008-0385-7.

Watanabe, M., and Coauthors, 2010: Improved climate simulation by MIROC5: Mean states, variability, and climate sensitivity. J. Climate, 23, 6312-6335.

Wiens, J. A., D. Stralberg, D. Jongsomjit, C. A. Howell, and M. A. Snyder, 2009: Niches, models, and climate change: Assessing the assumptions and uncertainties. Biogeography, Changing Climates, and Niche Evolution: Proceedings of an Arthur M. Sackler Colloquium of the National Academy of Sciences, National Academy of Sciences, 19729-19736.

Wu, W., A. H. Lynch, and A. Rivers, 2005: Estimating the uncertainty in a regional climate model related to initial and lateral boundary conditions. J. Climate, 18, 917-933.

Xie, S.-P., C. Deser, G. A. Vecchi, J. Ma, H. Teng, and A. T. Wittenberg, 2010: Global warming pattern formation: Sea surface temperature and rainfall. J. Climate, 23, 966986.

Xu, Z., and Z.-L. Yang, 2012: An improved dynamical downscaling method with GCM bias corrections and its validation with 30 years of climate simulations. J. Climate, 25, 6271-6286.

Yoshikane, T., F. Kimura, H. Kawase, and T. Nozawa, 2012: Verification of the performance of the pseudo-global-warming method for future climate changes during June in East Asia. SOLA, 8, 133-136, doi:10.2151/sola.2012-033.

Yukimoto, S., and Coauthors, 2011: Meteorological Research Institute-Earth System Model Version 1 (MRI-ESM1) Model description. Meteorological Research Institute Tech. Rep. 64, 83 pp.

Zeng, X., and A. Beljaars, 2005: A prognostic scheme of sea surface skin temperature for modeling and data assimilation. Geophys. Res. Lett., 32, L14605, doi:10.1029/2005GL023030.

Zhang, C., Y. Wang, A. Lauer, and K. Hamilton, 2012: Configuration and evaluation of the WRF model for the study of the Hawaii regional climate. Mon. Wea. Rev., 140, 32593277. 